\title{
Physiological roles of tryptophan in teleosts: current knowledge and perspectives for
} future studies

\author{
Hoseini, Seyyed Morteza; Pérez-Jiménez, Amelia; Costas, Benjamin; Azeredo, Rita; Gesto, Manuel
}

Published in:

Reviews in Aquaculture (Print)

Link to article, DOI:

$10.1111 /$ raq.12223

Publication date:

2019

Document Version

Peer reviewed version

Link back to DTU Orbit

Citation (APA):

Hoseini, S. M., Pérez-Jiménez, A., Costas, B., Azeredo, R., \& Gesto, M. (2019). Physiological roles of tryptophan in teleosts: current knowledge and perspectives for future studies. Reviews in Aquaculture (Print), $11(1)$, 3-24. https://doi.org/10.1111/raq.12223

\section{General rights}

Copyright and moral rights for the publications made accessible in the public portal are retained by the authors and/or other copyright owners and it is a condition of accessing publications that users recognise and abide by the legal requirements associated with these rights.

- Users may download and print one copy of any publication from the public portal for the purpose of private study or research.

- You may not further distribute the material or use it for any profit-making activity or commercial gain

- You may freely distribute the URL identifying the publication in the public portal 
1 Physiological roles of tryptophan in teleosts: Current knowledge and perspectives for 2 future studies

3 Short title: Roles of tryptophan in teleosts

4 Seyyed Morteza Hoseini ${ }^{\mathrm{a}^{*}}$, Amalia Pérez-Jiménez ${ }^{\mathrm{b}}$, Benjamin Costas ${ }^{\mathrm{c}, \mathrm{d}}$, Rita Azeredo ${ }^{\mathrm{d}, \mathrm{e}}$, 5 Manuel Gesto ${ }^{\text {f }}$

$6{ }^{a}$ Inland Waters Aquatic Stocks Research Center, Iranian Fisheries Science Research

7 Institute, Agricultural Research, Education and Extension Organization, Gorgan, Iran

8 b Departamento de Zoología, Universidad de Granada, Campus de Fuentenueva, 18071

9 Granada, Spain

$10{ }^{\mathrm{c}}$ Instituto de Ciências Biom édicas Abel Salazar, Universidade do Porto (ICBAS), Rua 11 de Jorge Viterbo Ferreira 228, 4050-313 Porto, Portugal.

$12{ }^{\mathrm{d}}$ Centro Interdisciplinar de Investigação Marinha e Ambiental (CIIMAR), Universidade do 13 Porto, Terminal de Cruzeiros do Porto de Leixões, Avenida General Norton de Matos 14 S/N, 4450-208 Matosinhos, Portugal.

15 e Departamento de Biologia, Faculdade de Ciências da Universidade do Porto (FCUP), 16 4169-007 Porto, Portugal

17 f Section for Aquaculture, The North Sea Research Centre, DTU Aqua, Technical 18 University of Denmark, Hirtshals, Denmark

19 *Corresponding author: Tel.: +989112750713, POB: 139; Fax: +981732240290. E-mail 20 address: seyyedmorteza.hoseini@gmail.com 


\section{Abstract}

23 Tryptophan is an essential amino acid with a huge functional versatility, in addition to

24 its participation in protein synthesis. Because of the complexity of its metabolism, and 25 the functional relevance of several of its metabolites, it directly or indirectly participates 26 in a wide array of physiological pathways. This amino acid is a precursor for the 27 synthesis of the neurotransmitter/neuromodulator serotonin $(5 \mathrm{HT})$, the hormone melatonin 28 and kynurenine and related compounds such as kynurenic acid, quinolinic acid or niacin. 29 Because of this, it has a key role in the regulation of processes ranging from the 30 neuroendocrine to the immune system in vertebrates. In aquaculture, extensive research 31 has been performed to optimize the levels of tryptophan in the commercial diets for 32 many fish species. Providing adequate levels of this amino acid is critically important for 33 fish growth but also for fish welfare, since tryptophan has been shown to modulate fish 34 behaviour, stress responses, and antioxidant and immune systems. Currently available data 35 suggest a wide variation in tryptophan requirements of different species ranging 0.3-1.2 $36 \%$ of dietary protein level, but recent evidence also show that fish tryptophan 37 requirements can greatly vary depending on the rearing conditions of the fish. We also 38 review here the participation of tryptophan and related metabolites in different 39 physiological functions that are crucial for fish welfare. The review covers the 40 involvement of tryptophan in 5HT- and melatonin-mediated functions, along with its 41 participation in the regulation of the immune system and its role as an antioxidant and 42 antitoxic agent in fish.

43 Keywords: tryptophan metabolism, serotonin, melatonin, antioxidant response, immune 44 mechanism

\section{Introduction}

46 Tryptophan is a neutral, aromatic amino acid that is essential for animals. As an 47 essential amino acid, tryptophan should be supplied via diet (Wilson, 2002). The teleost 48 requirements for the different amino acids is generally determined by means of growth 49 dose-response curves. By using this method, the dietary tryptophan requirement for 50 several teleost has been determined to range from 0.3 to $-1.2 \%$ of dietary protein 
51 (Table 1). In the literature, however, there are some contradictory data regarding 52 tryptophan requirement of a number of teleost fish species (Kim et al., 1987; Walton et 53 al., 1986; Walton et al., 1984; Johnston et al., 1990; Dabrowski, 1981; Tang et al., 54 2013; Fatma Abidi \& Khan, 2010; Murthy \& Varghese, 1997; Ahmed \& Khan, 2005; 55 Benakappa \& Varghese, 2003), indicating that dietary tryptophan requirement may depend on some unknown factors. On the other hand, tryptophan is the least abundant amino 57 acid in teleosts, indicating that the requirements of tryptophan for protein synthesis are 58 low. This suggests that growth dose-response curve might not be a suitable method for 59 the determination of tryptophan requirements in teleosts. Different observations in 60 previous studies are in support of this (see below).

61 In vertebrates, following dietary uptake, tryptophan may be used for protein synthesis 62 and/or may enter one of the three following pathways (Fig. 1): catabolism through the 63 kynurenine-niacin pathway, serotonin (5HT) synthesis and melatonin synthesis (Le Floc'h 64 et al., 2011). The balance among these pathways depends on physiological conditions 65 and/or external factors. While the routes from L-tryptophan to serotonin or melatonin are 66 well established in fish and known to be well conserved among vertebrates, much less 67 information is available regarding the fish kynurenin-niacin pathways. Some of the 68 components of the machinery of the mammalian kynurenin pathway are known to be 69 present in fish (see further sections of this review) and the general catabolic routes 70 through kynurenin are assumed to be similar to those in mammals. However, unlike 71 mammals, fish seem to be incapable of producing relevant amounts of niacin from L72 tryptophan and thus kynurenine-niacin pathway is mainly directed to remove excess 73 tryptophan, regulate the immune response and produce sexual pheromones (Cortés et al., 74 2016; Ng et al., 1997; Yambe et al., 2006).

75 Being the precursor of 5HT and melatonin, tryptophan modulates behaviour, mood and 76 stress responses in fish (Lepage et al., 2005a; Lepage et al., 2002; Winberg \& Lepage, 77 1998; Winberg et al., 2001; Azpeleta et al., 2010; Herrero et al., 2007; Lepage et al., 78 2005b). Overall, the different tryptophan metabolites have a wide range of physiological 79 roles including modulation of stress response, antioxidant system, immune response and 80 behavioural responses (Cortés et al., 2016; Höglund et al., 2005; Hoseini \& Hosseini, 
81 2010; Hoseini et al., 2016; Akhtar et al., 2013a; Akhtar et al., 2013b; Ciji et al., 2013b;

82 Ciji et al., 2012; Ciji et al., 2015; Tejpal et al., 2009; Wolkers et al., 2012; Hoseini et

83 al., 2012; Hosseini \& Hoseini, 2013; Azeredo et al., 2016). The knowledge regarding

84 tryptophan effects on teleosts is currently scarce compared to that from mammals. Many

85 studies in teleost fish focused in the modulation of the serotonergic system and the stress

86 response following short-term tryptophan administration. Moreover, available data show

87 several inconsistencies in results from different studies suggesting that there is a need for

88 more in -depth studies on tryptophan effects in teleosts.

89 In this review, the current knowledge on the effects of tryptophan on teleost's 90 serotonergic, melatonergic, kynurenine, antioxidant and immune systems was summarized

91 in order to provide a general insight on the topic for future reference.

\section{Tryptophan requirement, growth response and deficiency signs}

93 As an essential amino acid, dietary uptake is the main source of tryptophan for teleosts.

94 Feedstuffs have a wide range of tryptophan content. Wheat flour $(2.13 \%$ of dietary 95 protein), soybean oilcake $(1.48 \%$ of dietary protein), barley meal (1.47\% of dietary 96 protein), wheat gluten (1.3\% of dietary protein), cotton seed meal (1.27\% of dietary 97 protein), blood meal (1.14\% of dietary protein) and fishmeal (0.93-1.16\% of dietary 98 protein) are feedstuffs with high tryptophan content; whereas, corn $(0.68-0.82 \%$ of dietary 99 protein), hydrolysed feather meal (0.66\% of dietary protein), meat and/or bone meal $100(0.51-0.63 \%$ of dietary protein) and corn gluten $(0.47 \%$ of dietary protein $)$ have lower 101 tryptophan content (NRC, 2011). Using standard dose-growth response plot method 102 [purified or semi-purified diets with a range of tryptophan content; Wilson (2002)], 103 tryptophan requirement has been determined in a variety of teleost species, ranging 0.30$1041.30 \%$ of dietary protein (Table 1). Besides fish growth retardation, dietary tryptophan 105 deficiency leads to scoliosis, lordosis, cataract, opercular shortage, caudal fin root and 106 interference in mineral metabolism (Fagbenro \& Nwanna, 1999; Murthy \& Varghese, 107 1997; Poston \& Rumsey, 1983; Walton et al., 1984; Shanks et al., 1962).

108 Whole body amino acid profile of teleosts is suggestive of their dietary requirement 109 (Kaushik, 1998). It is strongly constant among fish with different size, and even among 
110 different species (Kaushik, 1998; Mambrini \& Kaushik, 1995; Wilson \& Cowey, 1985). 111 However, despite this relatively high similarity in the whole-body tryptophan content 112 tryptophan among different fish studies (in certain species or among different species), 113 reported dietary tryptophan requirements among different species show a wide variation 114 (0.3-1.3\% of dietary protein; Table 1). Moreover, there are some contradictions in the 115 data on dietary tryptophan requirements for certain species. For instance, in Cyprinus 116 carpio dietary tryptophan requirement has been determined to be 0.3 and $1.1 \%$ of dietary 117 protein, which stands for 4-fold variation (Dabrowski, 1981; Tang et al., 2013). Similarly 118 in Oncorhynchus mykiss, dietary tryptophan requirement has been reported to be 0.40$1190.71 \%$ of dietary protein (Kim et al., 1987; Walton et al., 1986; Walton et al., 1984; 120 Johnston et al., 1990). Dietary tryptophan levels of 0.9 and $1.13 \%$ of dietary protein 121 (Fatma Abidi \& Khan, 2010; Murthy \& Varghese, 1997) have been recommended as 122 required tryptophan levels for optimum growth performance in Labeo rohita. However, 123 Akhtar et al. (2013a) and Ciji et al. (2015) showed that L. rohita fed on diets 124 containing tryptophan levels of 3.05-5.17\% of dietary protein have significantly improved 125 weight gain compared to control fish (fed with diet containing 0.99\% tryptophan). In 126 Cirrhinus mrigala, dietary tryptophan levels of 0.95 and $1.2 \%$ of dietary protein were 127 reported as optimum dietary tryptophan levels for optimum growth of the fish. 128 Nevertheless, Tejpal et al. (2009) reported that this species showed elevated growth 129 performance when fed diets supplemented with exogenous dietary tryptophan levels of 1301.94 and $3.88 \%$ of dietary protein, regardless of basal dietary tryptophan content 131 (estimated to be $1 \%$ of dietary protein). Also, when these fish are reared under stressful 132 conditions (e.g. increased stocking density) higher exogenous tryptophan (7.75\% of 133 dietary protein) is required to assure maximum growth performance. Such inconsistencies 134 among dietary tryptophan requirement levels may be due to the fact that tryptophan is a 135 functional amino acid; i.e. tryptophan is required for some other vital processes beyond 136 protein synthesis in fish (Wu, 2009). Tryptophan is necessary for the synthesis of 5HT 137 and melatonin; it has antioxidant properties; it is necessary to counteract toxic substances; 138 and participates in immune function (see the following sections). A study on C. mrigala 139 (Tejpal et al., 2009) suggests that stress may increase fish demand for dietary 140 tryptophan. It could be partly due to increased serotonergic activity in teleosts under 
141 stressful conditions as well as an increased requirement for antioxidant capacity 142 (discussed below). Akhtar et al. (2013a) and Ciji et al. (2015) reported that growth 143 performance of $L$. rohita exposed to stressful conditions and water pollution improves 144 when fed diets containing 3.05-5.17\% tryptophan (\% of dietary protein) compared to that 145 containing $0.99 \%$ tryptophan (discussed below).

146 Practically, tryptophan deficiency signs (scoliosis, lordosis, cataract, opercular shortage, 147 caudal fin root and interference in mineral metabolism) are not reported in farmed fish; 148 because these signs are not disease-specific. However, it is necessary to monitor the 149 effects of dietary tryptophan supplementation on fish growth performance in farm, where 150 they face a variety of stressors (crowding, environmental and pollutant) that may increase 151 the need for dietary tryptophan (Fig. 2).

\section{Effects of tryptophan on 5HT synthesis, behaviour and stress response}

$1535 \mathrm{HT}$ is a monoamine which is simultaneously a neurotransmitter in the central nervous 154 system and a paracrine or endocrine signal in the gut and blood (Fernstrom, 2016). 5HT 155 pathway is relatively less significant in terms of tryptophan consumption, but 5HT 156 synthesis is essential regarding particular organs' well-functioning. Tryptophan uptake to 157 fish brain is somehow similar to mammals, which takes place through a stereospecific 158 and saturable carrier, but this carrier is used for other amino acids uptake, too 159 (Aldegunde et al., 1998). Increased tryptophan intake results in blood tryptophan 160 elevation which in turn increases tryptophan availability for uptake into the brain 161 (Johnston et al., 1990). Tryptophan is converted to 5HT by activity of tryptophan 162 hydroxylase and aromatic L-amino acid decarboxylase in the presence of vitamin $\mathrm{B}_{6}$ 163 (Johnston et al., 1990). Tryptophan hydroxylase is not saturated by its substrate, 164 tryptophan; therefore, elevated tryptophan intake causes constant increase in the brain 165 5HT and also 5-hydroxyindole acetic acid (5HIAA), the major serotonin metabolite 166 (Johnston et al., 1990).

167 About $95 \%$ of total body 5HT content is located in the gut (Le Floc'h et al., 2011), 168 particularly in the wall where the myenteric plexus is a major monoamine producer 169 (Caamano-Tubio et al., 2007). Moreover, some, but not all teleost species (Anderson \& 
170 Campbell, 1988; Yui et al., 1988), possess enterochromaffin cells in the gastrointestinal 171 mucosa which also account for this production thereby modulating surrounding cells 172 functions (Muñoz-Pérez et al., 2016). Peripheral 5HT synthesis is also complemented by 173 gills epithelium and both the head- and trunk- portions of the kidney (Caamano-Tubio et $174 a l ., 2007$ ) as well as liver and stomach (Nagai et al., 1997). In mammals, platelets can 175 internalize and store 5HT in granules by expressing the 5HT transporter (Sert). Upon 176 activation, these cells release the indoleamine which then mediates several actions from 177 vasodilation or vasoconstriction (Berger et al., 2009) to neutrophil recruitment 178 (Duerschmied et al., 2013). In contrast to mammals, fish blood-brain barrier allows the 179 passage of $5 \mathrm{HT}$ to the peripheral blood vessels but, to best of our knowledge, there is 180 no report on the presence of 5HT in fish thrombocytes (Fritsche et al., 1993). However, 181 because 5HT concentration in O. mykiss plasma was equal to that measured in whole 182 blood, it is assumed in fish that 5HT coming from peripheral tissues is stored in the 183 extracellular plasma pool (Caamano-Tubio et al., 2007). Fish intestinal contraction is 184 mediated by 5HT which, similar to mammals (Fernstrom, 2016), is mainly produced in 185 the myenteric plexus (Velarde et al., 2010). Since the presence of enterochromaffin cells 186 in teleosts is not transversal to all species, there is a serious lack of studies on the 187 function of enterochromaffin cells-produced 5HT. Still, given the homology between the 188 189 190 191 192 193 serotonergic systems of fish and mammals, it is likely that 5HT released by these cells might display the same pro-inflammatory and motility roles it does in higher vertebrates (Bertrand \& Bertrand, 2010; Gershon, 2013).

91 In the brain, serotonergic activity plays a major role in the hypothalamus-pituitaryinterrenal (HPI) axis. Serotonergic activity is usually measured by the rate of production of 5HIAA, the main 5HT metabolite, mediated by the monoamine oxidase (CaamanoTubio et al., 2007). Tryptophan administration stimulates brain 5HT synthesis; the synthetized 5HT can both stimulate and inhibit the HPI axis as previously observed in several studies with O. mykiss (Lepage et al., 2002; Winberg \& Lepage, 1998; Winberg et al., 2001), modulating aspects related to appetite and aggression (Höglund et al., 199 [through adrenocorticotropic hormone (ACTH) action] stimulated or inhibited cortisol 200 production in unstressed or stressed fish, respectively, as observed by enhanced 
201 serotonergic activity. Though this indirect effect induces the strongest responses, 5HT is 202 also able to directly stimulate cortisol production in interrenal cells (Lim et al., 2013). 203 Interestingly, levels of 5HIAA increased quite simultaneously or even previously to the 204 typical rise in plasma catecholamine concentration in stressed $O$. mykiss, suggesting that 205 5HT may trigger not only the HPI axis but also the response of the brain-sympathetic206 chromaffin axis in fish (Gesto et al., 2013). This effect is similar to that observed in 207 turkeys (Denbow et al., 1993) but not human (Rasmussen et al., 1983; Benedict et al., 208 1983).

209 Several studies in fish have shown that tryptophan administration increases serotonergic 210 activity characterized by increased 5HT and/or 5HIAA (Basic et al., 2013b; Herrero et 211 al., 2007; Höglund et al., 2007; Hseu et al., 2003; Lepage et al., 2002; Lepage et al., 212 2003), however, all these studies focused on the short-term tryptophan administration. 213 5HT alters voluntary feed intake, macronutrient selection, and stress response, and also 214 suppresses aggression (Rubio et al., 2006; Winberg \& Nilsson, 1993; Winberg et al., 215 1997; Øverli et al., 1998). Several studies demonstrated that tryptophan administration 216 increases 5HT and serotonergic activity and generates the effects similar to those caused 217 by direct 5HT administration. Gadus morhua showed increased brain 5HIAA and 218 5HIAA/5HT ratio and decreased aggressive behaviour when treated with tryptophan for 7 219 days (Höglund et al., 2005). Such an aggression-suppressive effect was also observed in 220 Brycon cephalus after 7 days tryptophan administration, although serotonergic activity was 221 not reported (Wolkers et al., 2012). Similarly, Epinephelus coioides treated with 222 tryptophan for 10 days showed suppressed aggressive behaviour and cannibalism along 223 with brain 5HT elevation (Hseu et al., 2003). Also, Dicentrarchus labrax showed 224 increase in 5HT synthesis and altered voluntary locomotion after 7 days tryptophan 225 administration (Herrero et al., 2007). These studies suggest that tryptophan affects teleost 226 behaviour via the serotonergic system; however, it is necessary to monitor long-term 227 tryptophan administration on the fish serotonergic response and behaviours.

228 Tryptophan requirement increases under stressful condition as a decrease in plasma 229 concentrations of tryptophan was observed in fish under stressful husbandry conditions 230 when compared to non-stressed fish (Aragao et al., 2008; Costas et al., 2008), thus 
231 dietary tryptophan supplementation may be a promising nutritional strategy for welfare 232 management in aquaculture (e.g. high rearing densities, transport and handling). Most of 233 the studies on tryptophan effects on the fish stress response have focused on short-term 234 tryptophan administration (7-15 days), but both acute and chronic stressors. In O. mykiss, 2357 days tryptophan administration had no significant effects on blood cortisol, but 236 suppressed post-acute-stress cortisol elevation, and this change in stress response seems to 237 be modulated via serotonergic activity and ACTH release (Lepage et al., 2002; Lepage et 238 al., 2003). Such an effect was observed in D. labrax fed a tryptophan-supplemented diet 239 for 7 days (Herrero et al., 2007). Also, in Salmo trutta, 7 days tryptophan administration 240 counteracted stress-induced anorexia (Höglund et al., 2007). But there are some studies 241 showing different results. In Oreochromis niloticus, 7 days feeding with a tryptophan242 supplemented diet increased serotonergic activity, decreased basal cortisol, but had no 243 significant effects on post stress cortisol (Martins et al., 2013). In Salmo salar, 7 days 244 tryptophan administration had no significant effects on basal and post stress (acute) brain 245 serotonin, 5HIAA and 5HIAA/5HT ratio, while it either stimulated or inhibited basal and 246 post stress plasma cortisol, depending on tryptophan level and time (Basic et al., 2013a). 247 Using the same tryptophan levels in G. morhua, Basic et al. (2013b) found elevated 248 5HIAA/5HT ratio depending on tryptophan concentration. Tryptophan had no significant 249 effects on basal cortisol, but mitigated post stress cortisol response 6 days, but not 1 and 2502 days, after tryptophan administration termination; suggesting long lasting effects 251 tryptophan on stress response. Similarly in S. salar, post stress cortisol levels decreased 2528 and 21 days after a 7-day period tryptophan administration (Höglund et al., 2017). The 253 importance of tryptophan administration time on serotonergic activity and cortisol 254 response has been also reported earlier in O. mykiss (Lepage et al., 2003). Interestingly, 255 Hoseini et al. (2016) reported increase in basal and post stress cortisol levels in 256 Acipenser persicus after 15 days feeding with tryptophan-supplemented diet $(0.5 \%$ of 257 diet). The same authors Hoseini and Hosseini (2010), however, reported a mitigation of 258 the stress response (serum cortisol and glucose) to a 7-days osmotic challenge in $C$. 259 carpio fed with similar tryptophan supplementation $(0.5 \%$ of diet). On the other hand, 260 only a few studies have evaluated the effects of long-term tryptophan administration on 261 the fish stress response. Morandini et al. (2015) found suppressed basal cortisol and 
262 increased brain serotonergic activity after 4 weeks tryptophan administration in 263 Cichlasoma dimerus, with no gender-specific trend. Tejpal et al. (2009), Akhtar et al. 264 (2013a) and Kumar et al. (2014) showed that 45-90 days tryptophan administration under 265 constant stressful conditions significantly suppressed cortisol and glucose responses and 266 improved growth performance in C. mrigala and L. rohita, suggesting the need for 267 higher tryptophan intake under stressful conditions to support maximum growth (Fig. 2).

268 Altogether, these studies show that there is a need for further research to find important 269 factors affecting tryptophan effects on the fish stress response, from brain serotonergic 270 activation to the release of cortisol. As mentioned above, timing appears to be a critical 271 factor; and due to time-dependent nature of serotonergic and cortisol responses to stress, 272 administration and sampling time should be taken into account when tryptophan effects 273 on acute stresses are investigated. Also, it seems that tryptophan administration level 274 needs to be considered as the above mentioned studies used a wide range $(0.3 \%-4.45$ $275 \%)$ of tryptophan supplementation. The matter is even more complicated when species 276 differences emerge, as two similar studies with similar tryptophan levels but different 277 species and exposure times showed different outputs (Basic et al., 2013a; Basic et al., 278 2013b).

\section{Tryptophan and melatonin synthesis}

280 Melatonin is produced from 5HT and is a rhythmic hormonal signal involved in the 281 synchronization of daily processes in which the pineal organ and retina play a central 282 role. Therefore, the amino acid tryptophan is also an indirect precursor for the 283 biosynthesis of the hormone melatonin ( $\mathrm{N}$-acetyl-5-methoxytryptamine), which could be 284 partly responsible for the effects observed after tryptophan administration in vertebrates. 285 In melatonin-producing cells, tryptophan is first transformed to 5HT (Fig. 1), which is 286 subsequently transformed into melatonin through two enzymatic steps: the transformation 287 of serotonin into $\mathrm{N}$-acetylserotonin, catalyzed by aryl-alkylamine $\mathrm{N}$-acetyl transferase

288 (AANAT; EC 2.3.1.87), and the subsequent conversion of $\mathrm{N}$-acetylserotonin into 289 melatonin, catalyzed by the hydroxyindole- $O$-methyltransferase (HIOMT; EC 2.1.1.4 ) 290 (Falcón et al., 2010). 
291 Pineal melatonin content elevates at night but decreases with light. Plus, because 292 melatonin is highly lipophilic and can therefore easily cross cell membranes, its plasma 293 levels oscillates parallel to pineal production (Falcón et al., 2011). On the other hand, 294 melatonin produced in the gut and retina is considered to have paracrine actions in those 295 tissues. However, gut melatonin seems somehow to have contribution in circulating melatonin level in fish. The gastrointestinal tract is a major melatonin production site. 297 Gastrointestinal cells are probably responsible for low, daytime levels of melatonin, while 298 pinealocytes light-sensitive melatonin production accounts for most of the night-time 299 hormone levels.

300 Other external and internal factors may account for melatonin activity modulation, though 301 instead of dictating rhythms, their action is limited to modifying rhythms amplitude 302 (Falcón et al., 2011). These can be temperature, hormones (melatonin itself) and 303 catecholamines (Falcón et al., 1991).

304 In teleosts, melatonin is engaged in several physiological processes other than those ruled 305 by circadian rhythms, from gut motility (Muñoz-Pérez et al., 2016) to osmoregulation 306 (Kulczykowska et al., 2006), immunity (Cuesta et al., 2008; Cuesta et al., 2007), stress 307 response (López-Patiño et al., 2013) and antioxidant capacity (Maitra \& Hasan, 2016), 308 feed intake (Pinillos et al., 2001; Velarde et al., 2010) and voluntary activity (Herrero et 309 al., 2007). Still, a large variability among responses, regulatory mechanisms and enzyme 310 distribution is observed in different teleost species.

311 Tryptophan administration has been shown to increase melatonin concentration in blood 312 and in other tissues such as the pineal gland or the gastrointestinal tract. For example, 313 oral administration of tryptophan has been shown to increase blood and tissue levels of 314 melatonin in birds and mammals (Paredes et al., 2007a; Sanchez et al., 2008; Huether et 315 al., 1992; Hajak et al., 1991). However, the effect of tryptophan administration on tissue 316 melatonin content could vary with the moment of the day or the reproductive stage 317 (Reiter et al., 1990; Guchhait \& Haldar, 2001). In fish, few existing studies resulted in 318 ambiguous conclusions. As in mammals, and similarly to what happens with 5HT, 319 tryptophan administration leads to increased melatonin production in the O. mykiss 320 enterochromaffin cells (Lepage et al., 2005b; Acuna-Castroviejo et al., 2014). Lepage et 321 al. (2005b) observed that melatonin levels were not different at night in O. mykiss fed 
322 tryptophan supplemented diets, in contrast to what happened during daytime. The authors

323 suggested two hypothesis; either i) intestinal melatonin production was decreased during 324 the night, or ii) melatonin itself acted in a negative feedback mechanism on pineal 325 hormone synthesis, the second being supported by observations in both birds (Wright \& 326 Preslock, 1975) and fish (Yanez \& Meissl, 1995). In contrast to O. mykiss, tryptophan 327 did not alter the hormone synthesis in the gut of the D. labrax (Herrero et al., 2007). 328 The authors suggested that the lack of increase in melatonin levels could be related to 329 the low level of tryptophan supplementation utilized in this study (tryptophan content in 330 the experimental diet was increased 2-fold with respect to the control diet), compared to 331 the previous study in fish [Lepage et al. (2005b); a 8-fold increase in the tryptophan332 enriched diet compared to the control diet].

333 Melatonin administration in fish and other vertebrates has been shown to induce some 334 stress-mitigating effects that resemble some of the effects observed after tryptophan 335 treatment. In birds and mammals, melatonin has been demonstrated to act as a central 336 and peripheral inhibitor of the hypothalamus-pituitary-adrenal (HPA) axis. Animals treated 337 with melatonin usually display an attenuated glucocorticoid response to stress 338 (Konakchieva et al., 1997; Torres-Farfan et al., 2003; Saito et al., 2005), in a similar 339 fashion to what is observed after tryptophan treatment [Dantzer and Moermede (1979); 340 Markus et al. (2002); also refer to previous section of this review]. In teleost fish, there 341 is also a body of evidence suggesting an anti-stress effect for melatonin at the level of 342 the HPI axis. In this regard, melatonin has been shown to inhibit and/or delay the 343 glucocorticoid response to stress in fish (Azpeleta et al., 2010; López-Patiño et al., 2013; 344 Conde-Sieira et al., 2014; Gesto et al., 2016). Again, this effect is similar to what is 345 observed after tryptophan treatment in fish (Herrero et al., 2007; Lepage et al., 2002; 346 Lepage et al., 2003). The mechanisms behind the observed melatonin effects on the 347 HPA/HPI axis are not well known. Some evidences in mammals point to a direct effect 348 of melatonin on the adrenal gland (Appa Rao et al., 2001; Torres-Farfan et al., 2003), 349 but there is also evidence suggesting that melatonin could have a direct action at the 350 brain, modulating the central pathways controlling the HPA/HPI axis (Xu et al., 1996; 351 Conde-Sieira et al., 2014; Gesto et al., 2016). 
352 Based on the similitudes between the stress response-mitigating effects of tryptophan and 353 melatonin treatment, and on the fact that tryptophan treatment increases melatonin levels 354 in vertebrates, it seems logical to think that melatonin could be at least partly 355 responsible for the stress-related effects of tryptophan, even when those effects are 356 generally attributed to the modulation of the serotonergic system (see previous section of 357 this review). However, the extent of melatonin participation in the effects induced by 358 tryptophan administration is not well known. In an elegant series of studies, Lepage et 359 al. (2005b) first suggested the possibility that melatonin could be mediating the stress360 and aggression- related effects of tryptophan in O. mykiss but, in a subsequent study, 361 they showed that most of the effect was probably being mediated by 5HT (Lepage et 362 al., 2005a). However, even when it seems clear that the involvement of melatonin is not 363 required for tryptophan to exert its stress-mitigating effects, a complementary action of 364 both serotonergic system and melatonin mediating the anti-stress action of tryptophan 365 administration should not be ruled out. Since the increase of melatonin levels after 366 tryptophan treatment seems to be dose-dependent (Herrero et al., 2007; Lepage et al., 367 2005a) a diet supplementation of tryptophan high enough to increase circulation/tissue 368 melatonin levels could be acting on the stress axis by both 5HT- and melatonin-mediated 369 mechanisms.

370 Melatonin could be also involved in other effects observed after tryptophan administration 371 in fish. For example, it could be mediating part of the effects of tryptophan regarding its 372 antioxidant properties and its effects on the immune system (see the following sections 373 in this review).

374 Furthermore, the potential effects of a sustained elevation of melatonin levels after long375 term tryptophan supplementation on fish growth and other physiological aspects are not 376 known. Besides its known involvement in the circadian and seasonal regulation of 377 different physiological processes (Falcón et al., 2007), melatonin has been also shown to 378 affect feeding and aggressive behaviour in fish (Munro, 1986; López-Olmeda et al., 379 2006; Pinillos et al., 2001). Further research would be needed to unveil whether any of 380 those aspects could be affected by a long-term increase in circulating melatonin levels in 381 fish. 


\section{Antioxidant capability of tryptophan}

383 In aquaculture, fish are exposed to multiple stressors derived from farming management

384 which can lead to reactive oxygen and nitrogen species (ROS and RNS) generation and then to an oxidative stress situation (Andrade et al., 2015; Castro et al., 2012; Morales

386

387

388

389

390

391

392

393

394

395

396

397

398

399

400

401

402

403

404

405

406

407

408

409

410

411 et al., 2004; Pérez-Jiménez et al., 2012; Wu et al., 2015). To counteract the possible negative effect of ROS overproduction, fish have evolved effective defence systems, consisting of both enzymatic defences such as superoxide dismutase (SOD; EC 1.15.1.1), catalase (CAT; EC 1.11.1.6), glutathione peroxidase (GPx; EC 1.11.1.9), glutathione reductase (GR; EC 1.8.1.7) and glucose-6-phosphate dehydrogenase (G6PDH; EC 1.1.1.49), and non-enzymatic antioxidant defences including vitamins, carotenoids, glutathione, thioredoxins, among others (Halliwell \& Gutteridge, 2015; Martínez-Álvarez et al., 2005). When oxidant agents exceed antioxidant defences, oxidative stress takes place and macromolecules in cells are damaged (Halliwell \& Gutteridge, 2015) and this fact might reduce growth performance and feed intake of animals, affect the quality and palatability of the final product, increase susceptibility to diseases or even lead to death, with the considerable economic loss for aquaculture producers (Andrade et al., 2015; Castro et al., 2012; Suárez et al., 2009). Although different strategies to mitigate oxidative stress effects can be adopted, nutrition approach plays a central role in this struggle (Oliva-Teles, 2012).

In fish, dietary supplementation with amino acids have been shown to improve antioxidant capacity enhancing the activity of main antioxidant enzymes and glutathione and decreasing oxidative damage in lipids and proteins, in different fish species (Coutinho et al., 2016; Giri et al., 2015; Pérez Jiménez et al., 2012). In the case of tryptophan, although there are many studies in different fish species focused on its nutritional requirements, role in behaviour, immunological properties or primary stress modulation (see the other sections of this review), very few reports are available about its effect on oxidative stress mitigation in fish (Akhtar et al., 2013a; Ciji et al., 2015; Jiang et al., 2016a; Jiang et al., 2015; Kumar et al., 2014; Wen et al., 2014).

It has been proposed that tryptophan exhibits antioxidant activity per se, since it reacts with highly reactive free radicals such as hydroxyl radicals and also modulates 
412 antioxidant enzyme activities (Del Angel-Meza et al., 2011; Peyrot \& Ducrocq, 2008;

413 Reyes-Gonzales et al., 2009). This fact has been shown both in vitro and in vivo studies

414 with terrestrial animals including mammals and birds. For example in rabbits, tryptophan

415 was effective in protecting the animals from the generation of free radicals and lipid

416 oxidative damage produced by a hypoxic myocardial injury (Narin et al., 2010). In

417 weaned piglets, increasing levels of dietary tryptophan ameliorated the hepatic oxidative

418 stress situations induced by injection of diquat (Mao et al., 2014). Liu et al. (2015)

419 observed that dietary tryptophan supplementation improved antioxidant status of ducks.

420 However, the mechanisms by which tryptophan exerts its antioxidant capacity are not

421 clear and need to be elucidated.

422 It is known that many of the potential antioxidant properties of tryptophan have been 423 attributed to its metabolites (Pérez-González et al., 2014). In this sense, 5HT and 424 melatonin, which are the main molecules synthetized from tryptophan, have been shown 425 as important antioxidants, although compared to melatonin, 5HT antioxidant capacity has 426 been less explored. Several studies, both in vitro and in vivo, have shown that $5 \mathrm{HT}$ can 427 act as a direct free radical scavenger, mainly of superoxide anion, hydrogen peroxide and 428 hydroxyl radicals and decrease lipids oxidative damage in several tissues (Daniels et al., 429 1996; Gülçin, 2008; Park et al., 2002). Moreover, 5HT has been shown to exert its 430 antioxidant action through chelating activities of ferrous ions (Sarikaya \& Gulcin, 2013). 431 Additionally, its direct metabolite, N-acetyl-serotonin, has been also indicated as 432 antioxidant molecule by different authors (Lezoualc'h et al., 1998; Moosmann et al., 433 1997).

434 Melatonin has different physiological roles in fish (see previous section in this review) 435 and it is the most important antioxidant molecule of those derived from tryptophan 436 metabolism. Unlike other antioxidants, it can scavenge up to ten free radicals, including 437 ROS and RNS, throughout a cascade of reactions that converts this indole in other 438 secondary and tertiary metabolites which are also able to neutralize free radicals (Tan et 439 al., 2015). Moreover, melatonin is not only an effective oxidant agent scavenger, but 440 also has the ability of activating main antioxidant enzymes such as SOD, CAT and GPx, 441 fact that has been demonstrated in humans and different terrestrial animals including 
442 mammals and birds (Barlow-Walden et al., 1995; Cabeza et al., 2001; Fjaerli et al., 443 1999; Paredes et al., 2007b).

444 In the same way, other studies about tryptophan metabolites, such as 5445 hydroxytryptophan, indole-3-acetic acid, 3-hydroxyanthranilic acid, 3-hydroxykynurenine or 446 xanthurenic acid have demonstrated their antioxidant capacities both as ROS scavengers 447 and modulation of antioxidant enzymes (Christen et al., 1990; Ferrari et al., 2014; 448 Matuszak et al., 1997; Pérez-González et al., 2015; Peyrot \& Ducrocq, 2008). Similarly, 449 some tryptophan-metabolizing enzymes, such as tryptophan 2,3-dioxygenase (TDO; EC 450 1.13.11.11) and indoleamine 2,3-dioxygenase (IDO; EC 1.13.11.52) has been considered 451 as antioxidant since in their reactions to catalyse the oxidative degradation of tryptophan, 452 they use the superoxide anion and hydrogen peroxide as cofactors (Batabyal \& Yeh, 453 2007; Britan et al., 2006; Hayaishi, 1996).

454 The general effects of dietary tryptophan supplementation (beyond to normal 455 requirements) in oxidative status of cultured fish have been scarcely studied (to our best 456 knowledge only in two fish species, L. rohita and Ctenopharyngodon idella). Akhtar et 457 al. (2013a) studied the effect of different levels of dietary tryptophan supplementation $(0$, 4580.7 and 1.4\%) in L. rohita under stressful conditions of temperature and salinity, 459 observing that SOD and CAT activities in liver and gills were reduced in tryptophan 460 supplemented groups, concluding that this amino acid had a role in the oxidative stress461 mitigation function. A later study in the same fish species under thermal stress and fed 462 on dietary tryptophan supplemented levels of $0,0.36,0.72$ and $1.42 \%$, confirmed the 463 previous observed results, observing SOD and CAT activities in liver and gills 464 significantly higher in the control groups that decreased with the increase of dietary 465 tryptophan inclusion (Kumar et al., 2014). In the same way, the activities observed for 466 SOD and CAT in muscle, liver and brain of L. rohita kept under nitrite exposure467 induced stress, increased in fish fed on $0 \%$ dietary tryptophan supplementation group, 468 whereas the activity of these antioxidant enzymes was decreased when fish were fed on $469 \quad 0.75$ and $1.5 \%$ of dietary tryptophan supplemented levels (Ciji et al., 2015). These 470 studies have used tryptophan levels higher than the species requirement suggesting that 
471 tryptophan requirement increases under oxidative conditions caused by environmental 472 stress and pollutants (Fig. 2).

473 In $C$. idella, Wen et al. (2014) evaluated the effects of dietary tryptophan (0.07, 0.17, $4740.31,0.4,0.52$ and $0.61 \%$ inclusion levels) in the intestinal oxidative status after stress 475 induced by environmental copper exposure. The fish fed on dietary tryptophan 476 supplementation increased CuZn-SOD and GPx activities and GSH contents and also 477 decreased the oxidative damage biomarkers for protein and lipids determined as protein 478 carbonyl and malondialdehyde (MDA) levels. Moreover, the relative gene expression 479 levels of CuZn-SOD and GPx were up-regulated with increasing of dietary tryptophan up 480 to a certain level, concluding that appropriate dietary levels of this amino acid improves 481 antioxidant status in fish. Additionally, in this study, the authors determined that up482 regulation of intestine antioxidant enzyme gene expression might be related to increase of 483 mRNA levels of Nrf2 observed in fish fed on dietary tryptophan levels up to $0.44 \%$. 484 Nrf2 is a signal molecule which has been related to expression of genes that encode 485 antioxidant enzymes (Lushchak, 2011). In this sense, a positive correlation between $486 \mathrm{CuZn-SOD}$ and GPx and gene expression level of Nrf2 was observed (Wen et al., 487 2014).

488 In later studies, Jiang et al. (2015) determined the effect of dietary tryptophan 489 supplementation on antioxidant defence mechanisms, oxidative damage biomarkers and 490 related signalling molecules, $\mathrm{Nrf} 2$ of gill in $C$. idella. The results showed that adequate 491 tryptophan levels improved gill oxidative status avoiding oxidative damage, since ROS 492 level decreased in fish fed on this amino acid compared to un-supplemented group. 493 These authors related the obtained results with the scavenger capacity of tryptophan per 494 se, neutralizing superoxide and hydroxyl radicals. Additionally, oxidative status 495 improvement was also justified by the results observed in GSH content, CuZn-SOD, 496 CAT, GPx, GST and GR activities, which were increased with dietary tryptophan 497 supplementation compared to the control group, and that were positively correlated to the 498 mRNA levels for these enzymes. As for the case of L. rohita, in C. idella, Nrf2 499 expression was also up-regulated by dietary tryptophan, which could partially justify the 500 increase in enzymatic antioxidant defenses. On the other hand, whereas in muscle of $C$. 
501 idella, responses for MDA levels, protein carbonyl content, GPx activity and expression 502 and GSH levels were similar to those previously observed in gills, no changes in either 503 SOD activity or gene expression were observed (Jiang et al., 2016b). Even more, CAT 504 activity and gene expression decreased at optimal dietary tryptophan levels, fact that was 505 justified by the complementary action of GPx.

506 Altogether, these results might suggest that amino acid supplementation in general, and 507 tryptophan in particular, is a very positive practice to improve animal welfare throughout 508 the optimization of the oxidative status. However, literature also includes studies with 509 contradictory results that point out the necessity of researching the conditions in which 510 the amino acid supplementation is performed (Deng et al., 2014; Jiang et al., 2016a; 511 Jiang et al., 2015; Jiang et al., 2016b; Peyrot \& Ducrocq, 2008). In fish species, Jiang 512 et al. (2015) and Jiang et al. (2016b) observed that excessive tryptophan inclusion in 513 diets leads to oxidative stress in gills and muscle of $C$. idella. So, when compared to 514 the optimum levels of tryptophan (0.31-0.4\%), excessive supplementation of this amino 515 acid $(0.61 \%)$ generate increased ROS content, MDA and protein carbonyl levels and low 516 GSH content and SOD, CAT, GPx, GST and GR activities and gene expression levels. 517 In these cases, the authors indicated that a possible motive for the generation of this 518 oxidative stress situation might be related to the production of 2,3-pyridine dicarboxylic 519 acid, a metabolite of tryptophan that has been demonstrated as stimulator of ROS 520 production (Sadeghnia et al., 2013; Santamaría et al., 2001).

521 Tryptophan antitoxic effects

522 A few studies have been conducted to find if dietary tryptophan administration 523 counteracts adverse effects of toxic substances in teleosts. Hoseini et al. (2012) showed 524 that dietary tryptophan administration significantly improved $C$. carpio survival upon 525 copper exposure. Also, tryptophan suppressed some adverse effects of copper toxicity on 526 serum cortisol, glucose and alanine transaminase (ALT). Fatahi and Hoseini (2013) found 527 that tryptophan supplementation significantly improves Rutilus caspicus survival following 528 acute copper exposure. Ciji et al. (2013b) demonstrated that dietary tryptophan 529 supplementation prevents nitrite-induced haematocrit, total protein, albumin and globulin 530 demotion in L. rohita. Ciji et al. (2013a) observed that dietary tryptophan 
531 supplementation in $L$. rohita mitigates growth deterioration, cortisol elevation, $\mathrm{T}_{4}$, 532 testosterone and estradiol demotion under nitrite exposure. Ciji et al. (2015) observed that 533 dietary tryptophan mitigates nitrite-induced growth and feed efficiency deterioration in $L$. 534 rohita. Also the added tryptophan significantly mitigated adverse effects of nitrite 535 exposure on blood white blood cell count; serum total protein, albumin, globulin, glucose and lysozyme; liver CAT, SOD, alanine transaminase (ALT) and aspartate transaminase

537 (AST); and muscle lactate dehydrogenase, ALT and AST.

538 Although the aforementioned studies suggest that tryptophan supplementation is beneficial 539 for fish when exposed to toxicants, the underlying mechanisms have not been studied. It 540 is known that some of those toxicants may interfere with brain serotonergic activity and 541 suppress 5HT synthesis as reported in C. carpio exposed to ambient copper (De Boeck 542 et al., 1995), Channa punctatus exposed to carbofuran (Gopal \& Ram, 1995) and 543 Oreochromis mossambicus exposed to mercury (Tsai et al., 1995). Therefore, the 544 serotonergic activity-promoting ability of tryptophan administration could help to 545 counteract the adverse effects of those toxic substances on the fish serotonergic activity. 546 This hypothesis is yet to be explored in fish.

547 Another potential explanation for the positive effects of tryptophan in fish exposed to 548 toxic substances might be mitigation of oxidative stress through its antioxidant property, 549 as described above. This is because the toxic agents used in the commented studies are 550 all known to cause oxidative damage in fish (Jia et al., 2015; Ciji et al., 2012; 551 Vutukuru et al., 2006; Wei \& Yang, 2016; Roméo et al., 2000; Sanchez et al., 2005; 552 Ciji et al., 2015).

\section{Tryptophan and immune response}

554 There has been growing interest in recent years in the role of tryptophan in both stress 555 and immune functions. The neuroendocrine-immune network is essential for homeostasis 556 during stress and infection and thus sustains a balanced immune response to effectively 557 clear the pathogen, while minimizing the damage to the host (Verburg-Van Kemenade et 558 al., 2009). A number of different hormones and cytokines, as well as their interactions, 559 are involved (Dhabhar, 2009). The energetic costs of the stress condition will activate 
other hormones involved in metabolic support, which may also have an influence on immune function. Therefore, leucocytes express glucocorticoid, adrenergic, cholinergic and opioid receptors, which make them sensitive to a wide repertoire of neuroendocrine responses (Verburg-Van Kemenade et al., 2009). For instance, glucocorticoids are known to have anti-inflammatory and immunosuppression actions in vertebrates. In this regard, cortisol alone can influence multiple aspects of immune defence mechanisms in fish. Cortisol inhibits lipopolysaccharides (LPS)-induced expression of pro-inflammatory cytokines and inducible nitric oxide (NO) synthase (Verburg-van Kemenade et al., 2011; Stolte et al., 2008). Cortisol also induces apoptosis and inhibits proliferation of immune cells (Verburg-Van Kemenade et al., 2009).

Metabolism and immunity are thus affected when fish are under stress and this together with sub-optimal dietary nitrogen formulations may affect fish welfare. A suitable balanced diet should provide adequate health and immune conditions to fish. However, little research has been done in optimizing the nitrogenous fraction of the diet in order to minimize welfare problems. Recent evidence shows that stressful husbandry conditions affect amino acid metabolism in fish, and under some stress situations an increase in the requirement of certain indispensable amino acid may occur (Conceiçao et al., 2012). Protein or amino acid requirements may also increase as a direct consequence of metabolic changes associated with inflammation and infection (Melchior et al., 2004; Sakkas et al., 2013). In fact, the dependence of the immune system upon the availability of amino acid is related to their role as signalling molecules essential for cellular function (Li et al., 2009). For instance, amino acids present important features in higher vertebrates as they regulate i) activation of $\mathrm{T}$ - and B-lymphocytes, natural-killer cells and macrophages; ii) cellular redox stage, gene expression and lymphocyte proliferation; and iii) production of antibodies, cytokines and cytokines substances as NO and superoxide (Wu, 2013). Moreover, both innate and adaptive immune responses are dependent upon adequate provision of amino acids for the synthesis of antigen-presenting molecules, immunoglobulins and cytokines (Sakkas et al., 2013).

Tryptophan in particular is an essential amino acid with recognized roles in both neuroendocrine and immune systems. Stress suppresses fish immunity and emerging 
590 evidences (see above) show that dietary tryptophan is required to cope with stress 591 (Aragao et al., 2008; Costas et al., 2008); also, 5HT, melatonin and $\mathrm{N}$-acetylserotonin, 592 products of tryptophan catabolism, can enhance host immunity by inhibiting the 593 production of superoxide, scavenging free radicals and attenuating the production of pro594 inflammatory cytokines (Perianayagam et al., 2005). However, tryptophan nutrition should 595 be carefully considered since recent evidence showed opposite outcomes. Azeredo et al. 596 (2016) tested the effects of tryptophan on the innate immune response of Senegalese sole 597 (Solea senegalensis) in an attempt to explore the links between immune and 598 neuroendocrine responses and to evaluate possible beneficial effects on disease resistance. 599 It was observed that tryptophan supplementation (i.e. a level of $2 \mathrm{x}$ above tryptophan 600 requirements) may promote the immune status and disease resistance in fish reared at 601 low $\left(12.5 \mathrm{~kg} / \mathrm{m}^{2}\right)$ or high $\left(31 \mathrm{~kg} / \mathrm{m}^{2}\right)$ densities. However, an even higher increase in 602 tryptophan supplementation (i.e. a level of $4 \mathrm{x}$ above tryptophan requirements) showed to 603 be beneficial in chronically stressed fish, whereas undisturbed individuals showed a 604 compromised immune status and lower disease resistance. Likewise, Costas et al. (2013) 605 observed a positive effect of tryptophan supplementation (i.e. a $0.5 \%$ increase in a dry 606 matter basis), which in combination with arginine, threonine and lysine, mitigated the 607 immunosuppressive effects attributed to chronic stress action by counteracting the 608 decrease in plasma lysozyme, complement and peroxidase activities observed in stressed 609 fish fed a non-supplemented diet. Moreover, L. rohita juveniles decreased total circulating 610 leucocytes and serum lysozyme activity following exposure to a sub-lethal concentration 611 of nitrite-nitrogen for 45 days, which was counteracted by dietary tryptophan (i.e. 0.75 612 and $1.5 \%$ increase in a dry matter basis) surplus (Ciji et al., 2015). Akhtar et al. 613 (2013a) and Akhtar et al. (2013b) showed that long-term (60 d) tryptophan 614 supplementation inhibits or suppresses chronic $(15 \mathrm{~d})$ thermal and/or salinity stress615 induced decrement in blood white blood cell count and respiratory burst activity; serum 616 total protein, albumin, globulin and lysozyme in L. rohita. Such effects might be due to 617 mitigation of stress response (serum cortisol) and suppression of oxidative stress (SOD 618 and CAT activity). In contrast, Sander lucioperca juveniles submitted to emersion stress 619 and long-term tryptophan treatment decreased both growth performance and plasma 620 lysozyme activity after 91 days of feeding (Mandiki et al., 2016), highlighting again the 
621 complexity of tryptophan effects in fish. All these studies suggest that immunosuppressive 622 conditions increase dietary tryptophan requirement (Fig. 2).

623 Thus, dietary tryptophan appears to modulate fish immune responses depending on the 624 species, level of supplementation in the diet and administration time when fish are reared 625 under standard husbandry conditions (i.e. undisturbed fish). S. senegalensis fed a 626 tryptophan supplemented diet (i.e. $0.5 \%$ increase in a dry matter basis) augmented plasma 627 lysozyme levels after 14 days of feeding whereas no changes were observed following 62828 days of tryptophan treatment (Costas et al., 2012). Interestingly, S. senegalensis fed a 629 similar diet with the same level of tryptophan supplementation increased plasma 630 peroxidase activity after 18 days of feeding, with no changes in plasma lysozyme or 631 complement activities. D. labrax fed a tryptophan supplemented diet (i.e. 0.5\% increase 632 in a dry matter basis) for 14 days were unable to improve both cellular (e.g. circulating 633 leucocyte numbers) and humoral (e.g. nitric oxide levels) mediated immune responses 634 (Machado et al., 2015). Similarly, A. persicus fed a $0.5 \%$ increase of tryptophan (dry 635 matter basis) did not change serum lysozyme and hemolytic activities after 5, 10 and 15 636 days of feeding (Hoseini et al., 2016). In contrast, several dietary tryptophan levels 637 induced detrimental responses in the young $C$. idella after 8 weeks of feeding (Wen et 638 al., 2014; Jiang et al., 2015). For instance, tryptophan deficiency or surplus negatively 639 affected gills and gut integrity by changing tight-junction proteins transcripts, which were 640 probably related to an increased gene expression of pro-inflammatory cytokines and 641 oxidative damage, compared to fish fed an optimum tryptophan level.

642 Tryptophan catabolism seems to play a critical role in the functions of both macrophages 643 and lymphocytes during infection. In mammals, while the protein-related pool of 644 tryptophan is kept constantly balanced between the processes of protein catabolism and 645 protein synthesis, about the $99 \%$ of tryptophan dietary intake is routed to the kynurenine 646 pathway (KP) of tryptophan catabolism (Macchiarulo et al., 2009). IDO catalyses the 647 first and rate-limiting step of the KP, and tryptophan catabolism by IDO seems to have 648 a major immunomodulatory effect during inflammation in mammals (Le Floc'h et al., 649 2011). In fact, tryptophan concentrations drop progressively in the plasma of animals 650 with inflammation (Melchior et al., 2004). The activation of IDO present in macrophages 
651 is induced by cytokines released by activated immune cells and leads to tryptophan 652 depletion. IDO activity is also responsible for superoxide anions consumption thus 653 exerting direct antioxidant activity (Le Floc'h et al., 2011). In fish, few studies have 654 explored the role of tryptophan during inflammation and infection. Changes in the 655 relative levels of metabolites such as choline, glycerophosphorylcholine and betaine, 656 which are metabolites involved in tryptophan metabolism, were observed by ${ }^{1} \mathrm{H}$ nuclear 657 magnetic resonance in the head-kidney of S. salar submitted to Aeromonas salmonicida 658 infection (Liu et al., 2016). D. labrax fed a 0.5\% (dry matter basis) tryptophan surplus 659 in the diet for 14 days and submitted to an intraperitoneal injection of Photobacterium 660 damselae subsp. piscicida decreased cellular responses and dropped plasma nitric oxide 661 and bactericidal activity compared to fish fed a control diet (Machado et al., 2015). 662 These authors hypothesized that a drop in nitric oxide levels could be related to the 663 inhibitory effect of 3OH-anthranilic acid (a tryptophan metabolite) on the expression of 664 inducible nitric oxide synthase, one of the main isoforms responsible for nitric oxide 665 production (Chiarugi et al., 2003). Machado et al. (2015) also observed a decreased 666 lymphocyte recruitment to the inflammatory focus at $24 \mathrm{~h}$ after injection with the 667 phlogistic agent in fish fed the tryptophan surplus compared to fish fed the control diet. 668 It has been hypothesized that this drop in lymphocyte numbers could be linked to a 669 decrease in $\mathrm{T}$ cells proliferation due to high expression of IDO in antigen presenting 670 cells. This enzyme can be expressed not only by macrophages but also in dendritic cells 671 (DCs), and $\mathrm{IDO}^{+} \mathrm{DCs}$ in mammals can potently and dominantly be suppressive for $\mathrm{T}$ 672 cell activation (Sharma et al., 2007). Indeed, the tryptophan degrading enzyme IDO plays 673 an important immunoregulatory role in higher vertebrates, and therefore in depth studies 674 are required to unravel its role in fish immune responses.

675 Since both stress and tryptophan are known to modulate immune function, an 676 immunomodulatory role for 5HT can be expected. In fact, this particular neurotransmitter 677 has been shown to be involved in both mammalian and teleost immune function (Khan 678 \& Deschaux, 1997; Mössner \& Lesch, 1998). For instance, scientific evidence showed 679 that 5HT can regulate a variety of immune responses including up-regulation of mitogen680 stimulated T- and B-lymphocyte proliferation (Aune et al., 1994; Iken et al., 1995; 681 Young \& Matthews, 1995). Moreover, 5HT also appears to act as an immunomodulator 
682 for its ability to stimulate or inhibit inflammation (Cloëz-Tayarani et al., 2003). However,

683 the functional role of 5HT in the fish immune system has been investigated much less. 684 Immunosuppressive effects induced by 5HT have been observed on the LPS- and 685 phytohaemagglutinin-stimulated proliferation of $O$. mykiss lymphocytes (Ferriere et al., 686 1996). Those same authors also described that $5 \mathrm{HT}_{1 \mathrm{~A}}$ receptors are expressed in trout 687 lymphocytes after mitogenic stimulation. Similarly, Duffy-Whritenour and Zelikoff (2008) 688 reported that endogenous (in vivo) and exogenous (in vitro) alterations in 5HT can 689 suppress splenic $\mathrm{T}$ - and B-lymphocyte proliferation in the Lepomis macrochirus, and 690 suggested a link between 5HT and the immune system in this particular teleost model. A 691 number of studies have also reported changes in the distribution of neuropeptides and 692 neurotransmitters in the digestive tract of parasitized fishes. For instance, Dezfuli et al. 693 (2000) and Dezfuli et al. (2008) observed 5HT immunoreactivities in immuno-related 694 cells of the intestine wall of parasitized S. trutta. Nevertheless, data proving evidence for 695 the role of 5HT in regulating the fish immune response is scarce and further studies 696 should focus on functional aspects such as cytokines secretion through the activation of 697 5HT receptors in fish leucocytes.

698 As commented above, melatonin is synthesized through 5HT and is involved in the 699 regulation of several important physiological and behavioural functions, including the 700 mammalian circadian rhythm, patterns of sleep, thermoregulation, reproduction and also 701 immune function (Carrillo-Vico et al., 2005). Regarding its role in immune function, 702 melatonin is for instance involved in the development of thymus and spleen and also 703 modulates innate and adaptive immune responses (Carrillo-Vico et al., 2005). Still, 704 knowledge regarding the actual fate of melatonin in the teleost immune functioning is 705 scarce. Esteban et al. (2006) reported clear effects of photoperiod on the humoral innate 706 immune system in two teleost fish, Sparus aurata and D. labrax, and provided evidence 707 that in fish, as in mammals, melatonin appears to play an important role in modulating 708 immune responses. Interestingly, seasonal changes in melatonin synthesis correlated with 709 changes in total white blood cell numbers and lysozyme activity in $O$. mykiss, but not 710 with the synthesis of ROS during the respiratory burst (Morgan et al., 2008). S. aurata 711 intraperitoneally injected with melatonin (1 or $10 \mathrm{mg}$ melatonin/kg of body weight) 712 increased the activity of peroxidase, phagocytosis and ROS production whereas the 
713 expression of immune-relevant genes such as interleukin-1 $\beta$, major histocompatibility 714 complex, virus-related response (interferon-regulatory factor-1 and $\mathrm{Mx}$ ) and lymphocyte 715 markers (immunoglobulin $\mathrm{M}$ and $\mathrm{T}$-cell receptor for $\mathrm{B}$ and $\mathrm{T}$ lymphocytes, respectively) 716 was up-regulated in the head-kidney of melatonin-injected fish 1 and 3 days post717 injection and decreased after 7 days (Cuesta et al., 2008). In vitro studies showed that $S$.

718 aurata and D. labrax head-kidney leucocytes incubated with low (similar to 719 physiological) doses of melatonin did not change innate immune parameters, whereas 720 very high (pharmacological) doses inhibited peroxidase activity and increased ROS 721 production (Cuesta et al., 2007). The melatonin receptors have been cloned in fish, and 722 partial or full-length sequences for the three high affinity melatonin receptor subtypes, 723 MT1, MT2 and Mel1c, have been obtained for several fish species (Esteban et al., 724 2013). The presence of MT1 receptors on carp leukocytes as well as significant effects 725 of melatonin on leucocyte migration and apoptosis during zymosan-induced peritonitis 726 were also observed in C. carpio (Kepka et al., 2015). Those authors described a potent 727 anti-inflammatory function for this hormone, whereas the observed melatonin induced 728 inhibition of leucocyte apoptosis indicates towards a dual function. Indeed, scientific 729 evidence suggests that neuroendocrine/immune interaction via melatonin is evolutionary 730 conserved but further studies are needed to clarify the role of melatonin in teleost 731 immune function.

\section{The kynurenine and niacin pathway}

733 As mentioned before, the $\mathrm{KP}$ is the dominant route for tryptophan degradation, 734 accounting for almost $95 \%$ of the tryptophan metabolized. Furthermore, it is consider to 735 be the pathway through which excess tryptophan is removed from the organism, as the 736 highest enzymatic activities occur in the liver where the portal blood supply is readily 737 absorbed by the hepatocytes (Fernstrom, 2016).

738 Tryptophan is firstly oxidized by one of two possible enzymes (Fig. 1): TDO (also 739 known as pyrrolase) or IDO. The produced $\mathrm{N}$-formylkynurenine is then converted to 740 kynurenine by arylformamidase, which can be metabolized by kynurenine 741 aminotransferase and thereby be converted into the bioactive kynurenic acid. However, 742 because this enzyme's $K_{\mathrm{m}}$ is very high, this branch of the KP will only occur in the 
743 presence of tryptophan supplementation (Fernstrom, 2016). Instead, kynurenine can be 744 further transformed in 3-hydroxykynurenine and 3-hydrxyanthranilic acid (both are 745 biologically active compounds) which will finally be oxidized into acroleyl aminofumarate 746 (2-amino-3-carboxymuconate semialdehyde). The following metabolic steps highly rely on 747 the organism uptake of dietary niacin. Acroleyl aminofumarate can either be fully 748 oxidized to picolinic acid and acetyl-CoA or it can be spontaneously cyclized to 749 quinolinic acid and subsequently to nicotinamide and nicotinic acid (Fernstrom, 2016; 750 Grohmann et al., 2003; Moffett \& Namboodiri, 2003a). In fish, tryptophan conversion to 751 niacin is limited and deficiency is known to impair growth and antioxidant capacity in 752 C. idella (Li et al., 2016a; Li et al., 2016b). Also, supplementing Ictalurus punctatus, 753 diets devoid of niacin with graded levels of tryptophan did not enhance this vitamin 754 endogenous synthesis ( $\mathrm{Ng}$ et al., 1997). While these are well-established steps in the 755 mammalian KP, only some of the components have been identified so far in teleost fish 756 (Cortés et al., 2016; Serrano \& Nagayama, 1992; Yambe et al., 2006; Yuasa et al., 757 2015). Therefore, whether the exact sequence of events is present and which mechanisms 758 regulate enzyme activities in lower vertebrates, is a matter of further investigation.

759 The two leading enzymes (TDO or IDO) differ in tissue distribution, substrate affinity 760 and specificity as well as regulation. TDO, almost exclusive of the liver, is more widely 761 conserved than IDO gene sequences and has already been sequenced in a few fish 762 species [S. salar, Oryzias latipes, Danio rerio and O. mykiss; Serrano and Nagayama 763 (1992)]. It is highly specific for tryptophan but its affinity is lower compared to IDO's 764 (Le Floc'h et al., 2011). Therefore, TDO reacts only to elevated hepatic amount of 765 tryptophan, particularly when it exceeds the requirement for protein and serotonin 766 synthesis (Murray, 2003). It is rate-limiting in this pathway and its activity is not only 767 induced by substrate availability, but also by glucocorticoids and glucagon (Badawy, 768 2002).

769 TDO activity is suppressed when IDO's is induced (Le Floc'h et al., 2011). IDO's 770 affinity to tryptophan is higher than TDO's, but it is not as specific towards this amino 771 acid. In fact, it is also able to accept other indole substrates such as 5HT, 5772 hydroxytryptophan or tryptamine (Yuasa et al., 2015). Although the contribution of IDO 
773 to overall activity of KP is small when compared to that of TDO, it acquires great 774 significance in conditions of immune stress. Indeed, tryptophan increasing levels do not 775 enhance IDO activity per se. Instead, IDO is induced by inflammatory stimulus such as 776 LPS or IFN- $\gamma$, which has been observed both in mammals (Grohmann et al., 2003) and 777 fish (Cortés et al., 2016). A growing interest has been laid on the KP, particularly when 778 initiated by IDO, due to important biological effects carried out by kynurenine 779 metabolites on the immune response (Grohmann et al., 2003; Moffett \& Namboodiri, 780 2003b; Munn \& Mellor, 2013) which makes this not only a tryptophan degradative 781 pathway but an important biosynthetic pathway, too.

782 The gene expression of IDO is ubiquitous in the rainbow trout, with the lowest levels 783 being detected in the spleen and kidney (Cortés et al., 2016). Its distribution is also 784 highly associated to its biological importance. Strong expression patterns in mucosal 785 tissues of the O. mykiss (skin, gills and gut) (Cortés et al., 2016) and its presence in 786 brain and gut macrophages and dendritic cells (Le Floc'h et al., 2011) reveal the 787 importance of IDO-mediated tryptophan metabolism in immune tolerance-leading 788 mechanisms indispensable in tissues where the host is in close and constant contact with 789 an array of microorganisms. Besides depleting tryptophan from the microenvironment, 790 which prevents microorganisms from utilizing it (Yuasa et al., 2007), immune tolerance 791 is carried out by tryptophan metabolites such as 3-hydroxykynurenine, 3792 hydroxyanthranilic acid and quinolinic acid which, among other effects, are able to 793 regulate $\mathrm{T}$ cell function and to modulate the oxidative status (Frumento et al., 2001).

794 Interestingly, a completely different physiological role has been attributed to kynurenine 795 which is that of being a pheromone. (Yambe et al. (2006)) observed that L-kynurenine 796 present in the urine of female ovulating Oncorhynchus masou is responsible for attracting 797 males, acting as a non-hormonal pheromone.

\section{Conclusions and future perspectives}

799 Tryptophan participates in different metabolic pathways involved in an array of 800 physiological functions. Moreover, tryptophan can be directly transformed into other 801 metabolites with important biological functions, including hormones such as melatonin or 
802

803

804

805

806

807

808

809

810

811

812

813

814

815

816

817

818

819

820

821

822

823

824

825

826

827

828

829

830

831

832

neurotransmitters/neuromodulators as 5HT, contributing even more to the versatility of this compound. Even when the literature available on the effects and requirements of this amino acid is extensive, several aspects of tryptophan physiology remain to be elucidated. Recent research showed that, besides species-dependent differences, the tryptophan dietary requirements may also vary depending on other factors such as the stress suffered by the fish or the water quality, highlighting the need of a proper evaluation of those factors when assessing the dietary requirements of a given species. Available data somehow suggest that the teleosts' tryptophan requirement may increase under stressful conditions because of the beneficial effects of this amino acid to suppress stress and toxicant effects, and to improve antioxidant and immune status (Fig. 2). However, in many cases, mechanistic studies are still needed to know to which extent those effects are directly attributable to tryptophan or to related compounds such as 5HT, melatonin, among others. Furthermore, the effects of tryptophan on those physiological aspects have been shown to be very complex and to depend on species, dose and administration timing, and negative effects associated to tryptophan supplementation have been also reported. Therefore, even when tryptophan supplementation could be a promising strategy to improve fish conditions in aquaculture, specific studies to find proper doses and application time for the different farmed species are still needed to optimize its use as a welfare-promoting supplement.

\section{Acknowledgements}

No fund was received for this article. There is no conflict of interest about this manuscript.

\section{References}

Acuna-Castroviejo D, Escames G, Venegas C, Diaz-Casado ME, Lima-Cabello E, Lopez LC, Rosales-Corral S, Tan DX, Reiter RJ (2014) Extrapineal melatonin: sources, regulation, and potential functions. Cell Mol Life Sci, 71, 2997-3025.

Ahmed I (2012) Dietary amino acid L-tryptophan requirement of fingerling Indian catfish, Heteropneustes fossilis (Bloch), estimated by growth and haemato-biochemical parameters. Fish Physiol. Biochem., 38, 1195-1209.

Ahmed I, Khan MA (2005) Dietary tryptophan requirement of fingerling Indian major carp, Cirrhinus mrigala (Hamilton). Aquac. Res., 36, 687-695. 
Akhtar M, Pal A, Sahu N, Ciji A, Meena D, Das P (2013a) Physiological responses of dietary tryptophan fed Labeo rohita to temperature and salinity stress. J. Anim. Physiol. Anim. Nutr. (Berl.), 97, 1075-1083.

Akhtar MS, Pal AK, Sahu NP, Ciji A (2013b) Hemato-immunological responses of Labeo rohita juveniles to temperature and salinity stress: Effect of dietary Ltryptophan. Israeli journal of aquaculture-Bamidgeh, 65, 1-8.

Akiyama T, Arai S, Murai T, Nose T (1985) Tryptophan requirement of chum salmon fry. Nippon suisan gakkaishi, 51, 1005-1008.

Aldegunde M, Garcia J, Soengas JL, Rozas G (1998) Uptake of tryptophan into brain of rainbow trout (Oncorhynchus mykiss). J. Exp. Zool., 282, 285-289.

Anderson C, Campbell G (1988) Immunohistochemical Study of 5-Ht-Containing Neurons in the Teleost Intestine - Relationship to the Presence of Enterochromaffin Cells. Cell Tissue Res, 254, 553-559.

Andrade T, Afonso A, Pérez-Jiménez A, Oliva-Teles A, de las Heras V, Mancera JM, Serradeiro R, Costas B (2015) Evaluation of different stocking densities in a Senegalese sole (Solea senegalensis) farm: implications for growth, humoral immune parameters and oxidative status. Aquaculture, 438, 6-11.

Appa Rao NV, Raza B, Prasad JK, Razi SS, Gottardo L, Ahmad MF, Nussdorfer GG (2001) Melatonin decreases glucocorticoid blood concentration in the rat and palm squirrel, acting directly on the adrenal gland. Biomedical research, 22, 115-117.

Aragao C, Corte-Real J, Costas B, Dinis MT, Conceição L (2008) Stress response and changes in amino acid requirements in Senegalese sole (Solea senegalensis Kaup 1858). Amino Acids, 34, 143-148.

Aune TM, Golden HW, McGrath KM (1994) Inhibitors of serotonin synthesis and antagonists of serotonin 1A receptors inhibit $\mathrm{T}$ lymphocyte function in vitro and cell-mediated immunity in vivo. The journal of immunology, 153, 489-498.

Azeredo R, Machado M, Moura J, Martos-Sitcha J, Mancera J, Peres H, Oliva-Teles A, Afonso A, Costas B (2016) Dietary tryptophan supplementation modulates immune status and disease resistance in senegalese sole, Solea senegalensis, reared at low or high density. In: International Meeting on Marine Research. Frontiers in Marine Science, Peniche, Portugal.

Azpeleta C, Martínez-Álvarez RM, Delgado MJ, Isorna E, De Pedro N (2010) Melatonin reduces locomotor activity and circulating cortisol in goldfish. Horm. Behav., 57, 323-329.

Badawy AA (2017) Kynurenine pathway of tryptophan metabolism: Regulatory and functional aspects. International journal of tryptophan research, $\mathbf{1 0 .}$

Badawy AAB (2002) Tryptophan metabolism in alcoholism. Nutr Res Rev, 15, 123-152.

Barlow-Walden L, Reiter R, Abe M, Pablos M, Menendez-Pelaez A, Chen L-D, Poeggeler B (1995) Melatonin stimulates brain glutathione peroxidase activity. Neurochem. Int., 26, 497-502.

Basic D, Krogdahl A, Schjolden J, Winberg S, Vindas MA, Hillestad M, Mayer I, Skjerve E, Höglund E (2013a) Short-and long-term effects of dietary 1-tryptophan supplementation on the neuroendocrine stress response in seawater-reared Atlantic salmon (Salmo salar). Aquaculture, 388, 8-13.

Basic D, Schjolden J, Krogdahl A, von Krogh K, Hillestad M, Winberg S, Mayer I, Skjerve E, Höglund E (2013b) Changes in regional brain monoaminergic activity 
and temporary down-regulation in stress response from dietary supplementation with L-tryptophan in Atlantic cod (Gadus morhua). Br. J. Nutr., 109, 2166-2174.

Batabyal D, Yeh S-R (2007) Human tryptophan dioxygenase: a comparison to indoleamine 2, 3-dioxygenase. J. Am. Chem. Soc., 129, 15690-15701.

Benakappa S, Varghese T (2003) Dietary requirement of tryptophan for growth and survival of the Indian major carp, Cirrhinus mrigala (Hamilton-Buchanan) fry. Indian J. Exp. Biol., 41, 1342-1345.

Benedict CR, Anderson GH, Sole MJ (1983) The influence of oral tyrosine and tryptophan feeding on plasma catecholamines in man. The American journal of clinical nutrition, 38, 429-435.

Berger M, Gray JA, Roth BL (2009) The Expanded Biology of Serotonin. Annu Rev Med, 60, 355-366.

Bertrand PP, Bertrand RL (2010) Serotonin release and uptake in the gastrointestinal tract. Auton Neurosci-Basic, 153, 47-57.

Britan A, Maffre V, Tone S, Drevet JR (2006) Quantitative and spatial differences in the expression of tryptophan-metabolizing enzymes in mouse epididymis. Cell Tissue Res., 324, 301-310.

Caamano-Tubio RI, Perez J, Ferreiro S, Aldegunde M (2007) Peripheral serotonin dynamics in the rainbow trout (Oncorhynchus mykiss). Comparative Biochemistry and Physiology C-Toxicology \& Pharmacology, 145, 245-255.

Cabeza J, Motilva V, Martín MaJ, de la Lastra CA (2001) Mechanisms involved in gastric protection of melatonin against oxidant stress by ischemia-reperfusion in rats. Life Sci., 68, 1405-1415.

Carrillo-Vico A, Guerrero JM, Lardone PJ, Reiter RJ (2005) A review of the multiple actions of melatonin on the immune system. Endocrine, 27, 189-200.

Castro C, Pérez-Jiménez A, Guerreiro I, Peres H, Castro-Cunha M, Oliva-Teles A (2012) Effects of temperature and dietary protein level on hepatic oxidative status of Senegalese sole juveniles (Solea senegalensis). Comparative biochemistry and physiology Part A: molecular \& integrative physiology, 163, 372-378.

Chiarugi A, Rovida E, Sbarba PD, Moroni F (2003) Tryptophan availability selectively limits NO-synthase induction in macrophages. J. Leukoc. Biol., 73, 172-177.

Christen S, Peterhans E, Stocker R (1990) Antioxidant activities of some tryptophan metabolites: possible implication for inflammatory diseases. Proceedings of the national academy of sciences, 87, 2506-2510.

Ciji A, Sahu N, Pal A, Akhtar M (2013a) Nitrite-induced alterations in sex steroids and thyroid hormones of Labeo rohita juveniles: effects of dietary vitamin E and Ltryptophan. Fish Physiol. Biochem., 39, 1297-1307.

Ciji A, Sahu N, Pal A, Akhtar M, Meena D (2013b) Haemato-immunological responses of nitrite exposed Labeo rohita fed diets supplemented with vitamin E and Ltryptophan, challenged by Aeromonas hydrophila. Isreali journal of aquaculture, 65, 889-897.

Ciji A, Sahu N, Pal A, Dasgupta S, Akhtar M (2012) Alterations in serum electrolytes, antioxidative enzymes and haematological parameters of Labeo rohita on shortterm exposure to sublethal dose of nitrite. Fish Physiol. Biochem., 38, 1355-1365. 
Ciji A, Sahu NP, Pal AK, Akhtar MS (2015) Dietary L-tryptophan modulates growth and immuno-metabolic status of Labeo rohita juveniles exposed to nitrite. Aquac. Res., 46, 2013-2024.

Cloëz-Tayarani I, Petit-Bertron AF, Venters HD, Cavaillon JM (2003) Differential effect of serotonin on cytokine production in lipopolysaccharide-stimulated human peripheral blood mononuclear cells: involvement of 5-hydroxytryptamine2A receptors. Int. Immunol., 15, 233-240.

Coloso R, Murillo-Gurrea D, Borlongan I, Catacutan M (2004) Tryptophan requirement of juvenile Asian sea bass Lates calcarifer. Journal of applied ichthyology, 20, 43-47.

Coloso RM, Tiro LB, Benitez LV (1992) Requirement for tryptophan by milkfish (Chanos chanos Forsskal) juveniles. Fish Physiol. Biochem., 10, 35-41.

Conceiçao LE, Aragão C, Dias J, Costas B, Terova G, Martins C, Tort L (2012) Dietary nitrogen and fish welfare. Fish Physiol. Biochem., 38, 119-141.

Conde-Sieira M, Muñoz J, López-Patiño M, Gesto M, Soengas J, Míguez J (2014) Oral administration of melatonin counteracts several of the effects of chronic stress in rainbow trout. Domest. Anim. Endocrinol., 46, 26-36.

Cortés J, Alvarez C, Santana P, Torres E, Mercado L (2016) Indoleamine 2, 3dioxygenase: First evidence of expression in rainbow trout (Oncorhynchus mykiss). Dev. Comp. Immunol., 65, 73-78.

Costas B, Aragão C, Dias J, Afonso A, Conceição LE (2013) Interactive effects of a high-quality protein diet and high stocking density on the stress response and some innate immune parameters of Senegalese sole Solea senegalensis. Fish Physiol. Biochem., 39, 1141-1151.

Costas B, Aragão C, Mancera JM, Dinis MT, Conceição LE (2008) High stocking density induces crowding stress and affects amino acid metabolism in Senegalese sole Solea senegalensis (Kaup 1858) juveniles. Aquac. Res., 39, 1-9.

Costas B, Aragão C, Soengas JL, Míguez JM, Rema P, Dias J, Afonso A, Conceição LE (2012) Effects of dietary amino acids and repeated handling on stress response and brain monoaminergic neurotransmitters in Senegalese sole (Solea senegalensis) juveniles. Comparative biochemistry and physiology Part A: Molecular \& integrative physiology, 161, 18-26.

Coutinho F, Castro C, Rufino-Palomares E, Ordóñez-Grande B, Gallardo M, Oliva-Teles A, Peres H (2016) Dietary glutamine supplementation effects on amino acid metabolism, intestinal nutrient absorption capacity and antioxidant response of gilthead sea bream (Sparus aurata) juveniles. Comparative biochemistry and physiology Part A: molecular \& integrative physiology, 191, 9-17.

Cuesta A, Cerezuela R, Esteban M, Meseguer J (2008) In vivo actions of melatonin on the innate immune parameters in the teleost fish gilthead seabream. J. Pineal Res., 45, 70-78.

Cuesta A, Rodríguez A, Calderón MV, Meseguer J, Esteban MÁ (2007) Effect of the pineal hormone melatonin on teleost fish phagocyte innate immune responses after in vitro treatment. Journal of experimental zoology Part A: ecological genetics and physiology, 307, 509-515.

Dabrowski K (1981) Tryptophan requirement of common carp (Cyprinus carpio L.) fry. Zeitschrift für Tierphysiologie Tierernährung und Futtermittelkunde, 46, 64-71. 
Daniels W, Van Rensburg S, Van Zyl J, Van Der Walt B, Taljaard J (1996) Free radical scavenging effects of melatonin and serotonin: possible mechanism. Neuroreport, 7, 1593-1596.

Dantzer R, Moermede P (1979) Effects of lithium on aggressive behaviour in domestic pigs. J. Vet. Pharmacol. Ther., 2, 299-303.

De Boeck G, Nilsson GE, Elofsson U, Vlaeminck A, Blust R (1995) Brain monoamine levels and energy status in common carp (Cyprinus carpio) after exposure to sublethal levels of copper. Aquat. Toxicol., 33, 265-277.

Del Angel-Meza A, Dávalos-Marín A, Ontiveros-Martinez L, Ortiz G, Beas-Zarate C, Chaparro-Huerta V, Torres-Mendoza B, Bitzer-Quintero O (2011) Protective effects of tryptophan on neuro-inflammation in rats after administering lipopolysaccharide. Biomed. Pharmacother., 65, 215-219.

Denbow D, Hobbs F, Hulet R, Graham P, Potter L (1993) Supplemental dietary Ltryptophan effects on growth, meat quality, and brain catecholamine and indoleamine concentrations in Turkeys. Br. Poult. Sci., 34, 715-724.

Deng Y-P, Jiang W-D, Liu Y, Jiang J, Kuang S-Y, Tang L, Wu P, Zhang Y-A, Feng L, Zhou X-Q (2014) Differential growth performance, intestinal antioxidant status and relative expression of $\mathrm{Nrf} 2$ and its target genes in young grass carp (Ctenopharyngodon idella) fed with graded levels of leucine. Aquaculture, 434, 66-73.

Dezfuli B, Arrighi S, Domeneghini C, Bosi G (2000) Immunohistochemical detection of neuromodulators in the intestine of Salmo trutta L. naturally infected with Cyathocephalus truncatus Pallas (Cestoda). J. Fish Dis., 23, 265-273.

Dezfuli BS, Giovinazzo G, Lui A, Giari L (2008) Inflammatory response to Dentitruncus truttae (Acanthocephala) in the intestine of brown trout. Fish Shellfish Immunol., 24, 726-733.

Dhabhar FS (2009) A hassle a day may keep the pathogens away: the fight-or-flight stress response and the augmentation of immune function. Integr. Comp. Biol., 49, 215-236.

Duerschmied D, Suidan GL, Demers M, Herr N, Carbo C, Brill A, Cifuni SM, Mauler M, Cicko S, Bader M, Idzko M, Bode C, Wagner DD (2013) Platelet serotonin promotes the recruitment of neutrophils to sites of acute inflammation in mice. Blood, 121, 1008-1015.

Duffy-Whritenour J, Zelikoff J (2008) Relationship between serotonin and the immune system in a teleost model. Brain. Behav. Immun., 22, 257-264.

Esteban MA, Cuesta A, Chaves-Pozo E, Meseguer J (2013) Influence of melatonin on the immune system of fish: a review. International journal of molecular sciences, 14, 7979-7999.

Esteban MA, Cuesta A, Rodríguez A, Meseguer J (2006) Effect of photoperiod on the fish innate immune system: a link between fish pineal gland and the immune system. J. Pineal Res., 41, 261-266.

Fagbenro O, Nwanna L (1999) Dietary tryptophan requirement of the African catfish, Clarias gariepinus. Journal of applied aquaculture, 9, 65-72.

Falcón J, Besseau L, Magnanou E, Herrero M-J, Nagai M, Boeuf G (2011) Melatonin, the time keeper: biosynthesis and effects in fish. Cybium, 35, 3-18. 
1014

1015

1016

1017

1018

1019

1020

1021

1022

1023

1024

1025

1026

1027

1028

1029

1030

1031

1032

1033

1034

1035

1036

1037

1038

1039

1040

1041

1042

1043

1044

1045

1046

1047

1048

1049

1050

1051

1052

1053

1054

1055

1056

1057
Falcón J, Besseau L, Sauzet S, Boeuf G (2007) Melatonin effects on the hypothalamopituitary axis in fish. Trends Endocrinol. Metab., 18, 81-88.

Falcón J, Migaud H, Munoz-Cueto JA, Carrillo M (2010) Current knowledge on the melatonin system in teleost fish. Gen. Comp. Endocrinol., 165, 469-482.

Falcón J, Thibault C, Martin C, Brun-Marmillon J, Claustrat B, Collin JP (1991) Regulation of melatonin production by catecholamines and adenosine in a photoreceptive pineal organ. An in vitro study in the pike and the trout. J. Pineal Res., 11, 123-134.

Fatahi S, Hoseini SM (2013) Effect of dietary tryptophan and betaine on tolerance of Caspian roach (Rutilus rutilus caspicus) to copper toxicity. International journal of aquatic biology, 1, 76-81.

Fatma Abidi S, Khan MA (2010) Dietary tryptophan requirement of fingerling rohu, Labeo rohita (Hamilton), based on growth and body composition. J. World. Aquac. Soc., 41, 700-709.

Fernstrom JD (2016) A perspective on the safety of supplemental tryptophan based on its metabolic fates. The journal of nutrition, 146, 2601S-2608S.

Ferrari R, Pugini SMP, Arce AIC, Costa EJX, Melo MP (2014) Metabolite of tryptophan promoting changes in EEG signal and the oxidative status of the brain. Cell Biochem. Funct., 32, 496-501.

Ferriere F, Khan N, Troutaud D, Deschaux P (1996) Serotonin modulation of lymphocyte proliferation via 5-HT1A receptors in rainbow trout (Oncorhynchus mykiss). Dev. Comp. Immunol., 20, 273-283.

Fjaerli O, Lund T, Østerud B (1999) The effect of melatonin on cellular activation processes in human blood. J. Pineal Res., 26, 50-55.

Fritsche R, Reid SG, Thomas S, Perry SF (1993) Serotonin-mediated release of catecholamines in the rainbow trout Oncorhynchus mykiss. J. Exp. Biol., 178, 191204.

Frumento G, Rotondo R, Tonetti M, Ferrara GB (2001) T cell proliferation is blocked by indoleamine 2,3-dioxygenase. Transplantation Proceedings, 33, 428-430.

Gaylord T, Rawles S, Davis K (2005) Dietary tryptophan requirement of hybrid striped bass (Morone chrysops $\times$ M. saxatilis). Aquacult Nutr, 11, 367-374.

Gershon MD (2013) 5-Hydroxytryptamine (serotonin) in the gastrointestinal tract. Curr Opin Endocrinol, 20, 14-21.

Gesto M, Álvarez-Otero R, Conde-Sieira M, Otero-Rodiño C, Usandizaga S, Soengas JL, Míguez JM, López-Patiño MA (2016) A simple melatonin treatment protocol attenuates the response to acute stress in the sole Solea senegalensis. Aquaculture, 452, 272-282.

Gesto M, Lopez-Patino MA, Hernandez J, Soengas JL, Miguez JM (2013) The response of brain serotonergic and dopaminergic systems to an acute stressor in rainbow trout: a time course study. J Exp Biol, 216, 4435-4442.

Giri SS, Sen SS, Chi C, Kim HJ, Yun S, Park SC, Sukumaran V (2015) Effect of dietary leucine on the growth parameters and expression of antioxidant, immune, and inflammatory genes in the head kidney of Labeo rohita fingerlings. Vet. Immunol. Immunopathol., 167, 36-43. 
1058

1059

1060

1061

1062

1063

1064

1065

1066

1067

1068

1069

1070

1071

1072

1073

1074

1075

1076

1077

1078

1079

1080

1081

1082

1083

1084

1085

1086

1087

1088

1089

1090

1091

1092

1093

1094

1095

1096

1097

1098

1099

1100

1101

1102

Gopal K, Ram M (1995) Alteration in the neurotransmitter levels in the brain of the freshwater snakehead fish (Channa punctatus) exposed to carbofuran. Ecotoxicology, 4, 1-4.

Grohmann U, Fallarino F, Puccetti P (2003) Tolerance, DCs and tryptophan: much ado about IDO. Trends Immunol., 24, 242-248.

Guchhait P, Haldar C (2001) A reproductive phase-dependent effect of dietary Ltryptophan on pineal gland and gonad of a nocturnal bird, Indian spotted owlet Athene brama. Acta Biol. Hung., 52, 1-7.

Gülçin I (2008) Measurement of antioxidant ability of melatonin and serotonin by the DMPD and CUPRAC methods as trolox equivalent. J. Enzyme Inhib. Med. Chem., 23, 871-876.

Hajak G, Huether G, Blanke J, Blömer M, Freyer C, Poeggeler B, Reimer A, Rodenbeck A, Schulz-Varszegi M, Rüther E (1991) The influence of intravenous L-tryptophan on plasma melatonin and sleep in men. Pharmacopsychiatry, 24, 1720.

Halliwell B, Gutteridge JM (2015) Free radicals in biology and medicine, Oxford University Press, USA, Oxford, UK.

Halver JE (1965) Tryptophan requirements of chinook, sockeye and silver salmon. $F A S E B, \mathbf{2 4}, 299$.

Hayaishi O (1996) Utilization of superoxide anion by indoleamine oxygenase-catalyzed tryptophan and indoleamine oxidation. In: Recent advances in tryptophan research. Springer, pp. 285-289.

Herrero M, Martínez F, Míguez J, Madrid J (2007) Response of plasma and gastrointestinal melatonin, plasma cortisol and activity rhythms of European sea bass (Dicentrarchus labrax) to dietary supplementation with tryptophan and melatonin. Journal of comparative physiology B, 177, 319-326.

Höglund E, Bakke MJ, Øverli Ø, Winberg S, Nilsson GE (2005) Suppression of aggressive behaviour in juvenile Atlantic cod (Gadus morhua) by 1-tryptophan supplementation. Aquaculture, 249, 525-531.

Höglund E, Øverli Ø, Andersson MÅ, Silva P, Laursen DC, Moltesen MM, Krogdahl A, Schjolden J, Winberg S, Vindas MA (2017) Dietary L-tryptophan leaves a lasting impression on the brain and the stress response. Br. J. Nutr., 117, 1351-1357.

Höglund E, Sørensen C, Bakke MJ, Nilsson GE, Øverli Ø (2007) Attenuation of stressinduced anorexia in brown trout (Salmo trutta) by pre-treatment with dietary Ltryptophan. Br. J. Nutr., 97, 786-789.

Hoseini SM, Hosseini SA (2010) Effect of dietary 1-tryptophan on osmotic stress tolerance in common carp, Cyprinus carpio, juveniles. Fish Physiol. Biochem., 36, 1061-1067.

Hoseini SM, Hosseini SA, Soudagar M (2012) Dietary tryptophan changes serum stress markers, enzyme activity, and ions concentration of wild common carp Cyprinus carpio exposed to ambient copper. Fish Physiol. Biochem., 38, 1419-1426.

Hoseini SM, Mirghaed AT, Mazandarani M, Zoheiri F (2016) Serum cortisol, glucose, thyroid hormones' and non-specific immune responses of Persian sturgeon, Acipenser persicus to exogenous tryptophan and acute stress. Aquaculture, 462, 17-23. 
Hosseini SA, Hoseini SM (2013) Effect of dietary tryptophan on stress response of wild common carp Cyprinus carpio L. World journal of fish and marine sciences, 5, 49-55.

Hseu JR, Lu FI, Su HM, Wang LS, Tsai CL, Hwang PP (2003) Effect of exogenous tryptophan on cannibalism, survival and growth in juvenile grouper, Epinephelus coioides. Aquaculture, 218, 251-263.

Huether G, Poeggeler B, Reimer A, George A (1992) Effect of tryptophan administration on circulating melatonin levels in chicks and rats: evidence for stimulation of melatonin synthesis and release in the gastrointestinal tract. Life Sci., 51, 945-953.

Iken K, Chheng S, Fargin A, Goulet A-C, Kouassi E (1995) Serotonin upregulates mitogen-stimulated B lymphocyte proliferation through 5-HT1A receptors. Cell. Immunol., 163, 1-9.

Jia R, Han C, Lei J-L, Liu B-L, Huang B, Huo H-H, Yin S-T (2015) Effects of nitrite exposure on haematological parameters, oxidative stress and apoptosis in juvenile turbot (Scophthalmus maximus). Aquat. Toxicol., 169, 1-9.

Jiang W-D, Feng L, Qu B, Wu P, Kuang S-Y, Jiang J, Tang L, Tang W-N, Zhang YA, Zhou X-Q (2016a) Changes in integrity of the gill during histidine deficiency or excess due to depression of cellular anti-oxidative ability, induction of apoptosis, inflammation and impair of cell-cell tight junctions related to Nrf2, TOR and NF- $\mathrm{KB}$ signaling in fish. Fish Shellfish Immunol., 56, 111-122.

Jiang W-D, Wen H-L, Liu Y, Jiang J, Kuang S-Y, Wu P, Zhao J, Tang L, Tang W-N, Zhang Y-A (2015) The tight junction protein transcript abundance changes and oxidative damage by tryptophan deficiency or excess are related to the modulation of the signalling molecules, NF- $\mathrm{kB}$ p65, TOR, caspase- $(3,8,9)$ and Nrf2 mRNA levels, in the gill of young grass carp (Ctenopharyngodon idellus). Fish Shellfish Immunol., 46, 168-180.

Jiang W-D, Wen H-L, Liu Y, Jiang J, Wu P, Zhao J, Kuang S-Y, Tang L, Tang W-N, Zhang Y-A (2016b) Enhanced muscle nutrient content and flesh quality, resulting from tryptophan, is associated with anti-oxidative damage referred to the Nrf2 and TOR signalling factors in young grass carp (Ctenopharyngodon idella): Avoid tryptophan deficiency or excess. Food Chem., 199, 210-219.

Johnston WL, Atkinson JL, Hilton JW, Were KE (1990) Effect of dietary tryptophan on plasma and brain tryptophan, brain serotonin, and brain 5-hydroxyindoleacetic acid in rainbow trout. The journal of nutritional biochemistry, 1, 49-54.

Kaushik SJ (1998) Whole body amino acid composition of European seabass (Dicentrarchus labrax), gilthead seabream (Sparus aurata) and turbot (Psetta maxima) with an estimation of their IAA requirement profiles. Aquat. Living Resour., 11, 355-358.

Kepka M, Szwejser E, Pijanowski L, Verburg-van Kemenade BL, Chadzinska M (2015) A role for melatonin in maintaining the pro-and anti-inflammatory balance by influencing leukocyte migration and apoptosis in carp. Dev. Comp. Immunol., 53, 179-190.

Khan N, Deschaux P (1997) Role of serotonin in fish immunomodulation. J. Exp. Biol., 200, 1833-1838.

Kim K-i, Kayes TB, Amundson CH (1987) Effects of dietary tryptophan levels on growth, feed/gain, carcass composition and liver glutamate dehydrogenase activity 
in rainbow trout (Salmo gairdneri). Comparative biochemistry and physiology Part

Konakchieva R, Mitev Y, Almeida OF, Patchev VK (1997) Chronic melatonin treatment and the hypothalamo-pituitary-adrenal axis in the rat: attenuation of the secretory response to stress and effects on hypothalamic neuropeptide content and release. Biology of the cell, 89, 587-596.

Kulczykowska E, Kalamarz H, Warne JM, Balment RJ (2006) Role of melatonin in fish osmoregulation: Towards a new action of the hormone. J Exp Zool Part A, 305a, 145-145.

Kumar P, Saurabh S, Pal A, Sahu N, Arasu A (2014) Stress mitigating and growth enhancing effect of dietary tryptophan in rohu (Labeo rohita, Hamilton, 1822) fingerlings. Fish Physiol. Biochem., 40, 1325-1338.

Le Floc'h N, Otten W, Merlot E (2011) Tryptophan metabolism, from nutrition to potential therapeutic applications. Amino Acids, 41, 1195-1205.

Lepage O, Larson ET, Mayer I, Winberg S (2005a) Serotonin, but not melatonin, plays a role in shaping dominant-subordinate relationships and aggression in rainbow trout. Horm. Behav., 48, 233-242.

Lepage O, Larson ET, Mayer I, Winberg S (2005b) Tryptophan affects both gastrointestinal melatonin production and interrenal activity in stressed and nonstressed rainbow trout. J. Pineal Res., 38, 264-271.

Lepage O, Tottmar O, Winberg S (2002) Elevated dietary intake of L-tryptophan counteracts the stress-induced elevation of plasma cortisol in rainbow trout (Oncorhynchus mykiss). J. Exp. Biol., 205, 3679-3687.

Lepage O, Vílchez IM, Pottinger TG, Winberg S (2003) Time-course of the effect of dietary L-tryptophan on plasma cortisol levels in rainbow trout Oncorhynchus mykiss. J. Exp. Biol., 206, 3589-3599.

Lezoualc'h F, Sparapani M, Behl C (1998) N-acetyl-serotonin (normelatonin) and melatonin protect neurons against oxidative challenges and suppress the activity of the transcription factor NF-кB. J. Pineal Res., 24, 168-178.

Li P, Mai KS, Trushenski J, Wu GY (2009) New developments in fish amino acid nutrition: towards functional and environmentally oriented aquafeeds. Amino Acids, 37, 43-53.

Li SQ, Feng L, Jiang WD, Liu Y, Jiang J, Wu P, Kuang SY, Tang L, Tang WN, Zhang YA, Zhou XQ (2016a) Deficiency of dietary niacin impaired gill immunity and antioxidant capacity, and changes its tight junction proteins via regulating NFkappa B, TOR, Nrf2 and MLCK signaling pathways in young grass carp (Ctenopharyngodon idella). Fish Shellfish Immun, 55, 212-222.

Li SQ, Feng L, Jiang WD, Liu Y, Wu P, Zhao J, Kuang SY, Jiang J, Tang L, Tang WN, Zhang YA, Zhou XQ (2016b) Deficiency of dietary niacin decreases digestion and absorption capacities via declining the digestive and brush border enzyme activities and downregulating those enzyme gene transcription related to TOR pathway of the hepatopancreas and intestine in young grass carp (Ctenopharyngodon idella). Aquacult Nutr, 22, 1267-1282.

Lim JE, Porteus CS, Bernier NJ (2013) Serotonin directly stimulates cortisol secretion from the interrenals in goldfish. General and Comparative Endocrinology, 192, 246-255. 
Liu P-f, Du Y, Meng L, Li X, Liu Y (2016) Metabolic profiling in kidneys of Atlantic salmon infected with Aeromonas salmonicida based on $1 \mathrm{H}$ NMR. Fish Shellfish Immunol., 58, 292-301.

Liu Y, Yuan J, Zhang L, Zhang Y, Cai S, Yu J, Xia Z (2015) Effects of tryptophan supplementation on growth performance, antioxidative activity, and meat quality of ducks under high stocking density. Poult. Sci., 94, 1894-1901.

López-Olmeda J, Madrid J, Sánchez-Vázquez F (2006) Melatonin effects on food intake and activity rhythms in two fish species with different activity patterns: Diurnal (goldfish) and nocturnal (tench). Comparative biochemistry and physiology Part A: molecular \& integrative physiology, 144, 180-187.

López-Patiño MA, Conde-Sieira M, Gesto M, Librán-Pérez M, Soengas JL, Míguez JM (2013) Melatonin partially minimizes the adverse stress effects in Senegalese sole (Solea senegalensis). Aquaculture, 388, 165-172.

Lushchak VI (2011) Environmentally induced oxidative stress in aquatic animals. Aquat. Toxicol., 101, 13-30.

Macchiarulo A, Camaioni E, Nuti R, Pellicciari R (2009) Highlights at the gate of tryptophan catabolism: a review on the mechanisms of activation and regulation of indoleamine 2, 3-dioxygenase (IDO), a novel target in cancer disease. Amino Acids, 37, 219-229.

Machado M, Azeredo R, Díaz-Rosales P, Afonso A, Peres H, Oliva-Teles A, Costas B (2015) Dietary tryptophan and methionine as modulators of European seabass (Dicentrarchus labrax) immune status and inflammatory response. Fish Shellfish Immunol., 42, 353-362.

Maitra SK, Hasan KN (2016) The Role of Melatonin as a Hormone and an Antioxidant in the Control of Fish Reproduction. Frontiers in Endocrinology, 7, 38.

Mambrini M, Kaushik S (1995) Indispensable amino acid requirements of fish: correspondence between quantitative data and amino acid profiles of tissue proteins. Journal of applied ichthyology, 11, 240-247.

Mandiki SNM, Redivo B, Baekelandt S, Douxfils J, Lund I, Höglund E, Kestemont P (2016) Long-term tryptophan supplementation decreased the welfare and innate immune status of pikeperch juveniles. Fish Shellfish Immunol., 53, 113-114.

Mao X, Lv M, Yu B, He J, Zheng P, Yu J, Wang Q, Chen D (2014) The effect of dietary tryptophan levels on oxidative stress of liver induced by diquat in weaned piglets. Journal of animal science and biotechnology, 5, 49.

Markus CR, Olivier B, de Haan EH (2002) Whey protein rich in $\alpha$-lactalbumin increases the ratio of plasma tryptophan to the sum of the other large neutral amino acids and improves cognitive performance in stress-vulnerable subjects. The American journal of clinical nutrition, 75, 1051-1056.

Martínez-Álvarez RM, Morales AE, Sanz A (2005) Antioxidant defenses in fish: biotic and abiotic factors. Rev. Fish Biol. Fish., 15, 75-88.

Martins CI, Silva PI, Costas B, Larsen BK, Santos GA, Conceição LE, Dias J, Øverli $\varnothing$, Höglund E, Schrama JW (2013) The effect of tryptophan supplemented diets on brain serotonergic activity and plasma cortisol under undisturbed and stressed conditions in grouped-housed Nile tilapia Oreochromis niloticus. Aquaculture, 400, 129-134. 
Matuszak Z, Reszka KJ, Chignell CF (1997) Reaction of melatonin and related indoles with hydroxyl radicals: EPR and spin trapping investigations. Free Radic. Biol. Med., 23, 367-372.

Melchior D, Sève B, Floc'h L (2004) Chronic lung inflammation affects plasma amino acid concentrations in pigs. J. Anim. Sci., 82, 1091-1099.

Moffett JR, Namboodiri M (2003a) Tryptophan and the immune response. Immunol. Cell Biol., 81, 247-265.

Moffett JR, Namboodiri MA (2003b) Tryptophan and the immune response. Immunol Cell Biol, 81, 247-265.

Moosmann B, Uhr M, Behl C (1997) Neuroprotective potential of aromatic alcohols against oxidative cell death. FEBS Lett., 413, 467-472.

Morales AE, Pérez-Jiménez A, Hidalgo MC, Abellán E, Cardenete G (2004) Oxidative stress and antioxidant defenses after prolonged starvation in Dentex dentex liver. Comparative biochemistry and physiology Part C: toxicology \& pharmacology, 139, $153-161$.

Morandini L, Ramallo MR, Moreira RG, Höcht C, Somoza GM, Silva A, Pandolfi M (2015) Serotonergic outcome, stress and sexual steroid hormones, and growth in a South American cichlid fish fed with an L-tryptophan enriched diet. Gen. Comp. Endocrinol., 223, 27-37.

Morgan AL, Thompson K, Auchinachie N, Migaud H (2008) The effect of seasonality on normal haematological and innate immune parameters of rainbow trout Oncorhynchus mykiss L. Fish Shellfish Immunol., 25, 791-799.

Mössner R, Lesch K-P (1998) Role of serotonin in the immune system and in neuroimmune interactions. Brain. Behav. Immun., 12, 249-271.

Munn DH, Mellor AL (2013) Indoleamine 2,3 dioxygenase and metabolic control of immune responses. Trends Immunol, 34, 137-143.

Muñoz-Pérez JL, López-Patiño MA, Álvarez-Otero R, Gesto M, Soengas JL, Míguez JM (2016) Characterization of melatonin synthesis in the gastrointestinal tract of rainbow trout (Oncorhynchus mykiss): distribution, relation with serotonin, daily rhythms and photoperiod regulation. Journal of comparative physiology B, 186, 471-484.

Munro A (1986) Effects of melatonin, serotonin, and naloxone on aggression in isolated cichlid fish (Aequidens pulcher). J. Pineal Res., 3, 257-262.

Murray MF (2003) Tryptophan depletion and HIV infection: a metabolic link to pathogenesis. Lancet Infect Dis, 3, 644-652.

Murthy HS, Varghese T (1997) Dietary tryptophan requirement for the growth of rohu, Labeo rohita. Journal of applied aquaculture, 7, 71-79.

Nagai T, Hamada M, Kai N, Tanoue Y, Nagayama F (1997) Organ distribution of tryptophan hydroxylase activity in several fish. Fisheries Sci, 63, 652-653.

Narin F, Narin N, BAŞARSLAN F, Baykan A, Sezer S, Akgün H, Akin A, AKÇAKUŞ M, Ceyran H (2010) The effect of L-tryptophan on the heart in rabbits via chronic hypoxia. Turkish journal of medical Sciences, 40, 257-263.

Ng W-K, Serrini G, Zhang Z, Wilson RP (1997) Niacin requirement and inability of tryptophan to act as a precursor of NAD+ in channel catfish, Ictalurus punctatus. Aquaculture, 152, 273-285. 
NRC (2011) Nutrient requirement of fish and shrimp, The National Academies Press, Washington DC.

Oliva-Teles A (2012) Nutrition and health of aquaculture fish. J. Fish Dis., 35, 83-108.

Øverli Ø, Winberg S, Damsård B, Jobling M (1998) Food intake and spontaneous swimming activity in Arctic char (Salvelinus alpinus): role of brain serotonergic activity and social interactions. Can. J. Zool., 76, 1366-1370.

Paredes SD, Terrón MP, Cubero J, Valero V, Barriga C, Reiter RJ, Rodríguez AB (2007a) Tryptophan increases nocturnal rest and affects melatonin and serotonin serum levels in old ringdove. Physiol. Behav., 90, 576-582.

Paredes SD, Terrón MP, Marchena AM, Barriga C, Pariente JA, Reiter RJ, Rodríguez AB (2007b) Tryptophan modulates cell viability, phagocytosis and oxidative metabolism in old ringdoves. Basic Clin. Pharmacol. Toxicol., 101, 56-62.

Park JW, Youn YC, Kwon OS, Jang YY, Han ES, Lee CS (2002) Protective effect of serotonin on 6-hydroxydopamine-and dopamine-induced oxidative damage of brain mitochondria and synaptosomes and PC12 cells. Neurochem. Int., 40, 223-233.

Pérez-González A, Alvarez-Idaboy JR, Galano A (2015) Free-radical scavenging by tryptophan and its metabolites through electron transfer based processes. Journal of molecular modeling, 21, 213.

Pérez-González A, Muñoz-Rugeles L, Alvarez-Idaboy J (2014) Tryptophan: antioxidant or target of oxidative stress? A quantum chemistry elucidation. RSC Advances, 4, 56128-56131.

Pérez-Jiménez A, Peres H, Rubio VC, Oliva-Teles A (2012) The effect of hypoxia on intermediary metabolism and oxidative status in gilthead sea bream (Sparus aurata) fed on diets supplemented with methionine and white tea. Comparative biochemistry and physiology Part C: toxicology \& pharmacology, 155, 506-516.

Pérez Jiménez A, Peres H, Cruz Rubio V, Oliva-Teles A (2012) The effect of dietary methionine and white tea on oxidative status of gilthead sea bream (Sparus aurata). Br. J. Nutr., 108, 1202-1209.

Perianayagam M, Oxenkrug G, Jaber B (2005) Immune-modulating effects of melatonin, N-acetylserotonin, and N-acetyldopomine. Ann. N. Y. Acad. Sci., 1053, 386-393.

Pewitt E, Castillo S, Velásquez A, Gatlin DM (2016) The dietary tryptophan requirement of juvenile red drum, Sciaenops ocellatus. Aquaculture.

Peyrot F, Ducrocq C (2008) Potential role of tryptophan derivatives in stress responses characterized by the generation of reactive oxygen and nitrogen species. J. Pineal Res., 45, 235-246.

Pinillos M, De Pedro N, Alonso-Gómez A, Alonso-Bedate M, Delgado M (2001) Food intake inhibition by melatonin in goldfish (Carassius auratus). Physiol. Behav., 72, 629-634.

Poston HA, Rumsey GL (1983) Factors affecting dietary requirement and deficiency signs of L-tryptophan in rainbow trout. The journal of nutrition, 113, 2568-2577.

Rasmussen D, Ishizuka B, Quigley M, Yen S (1983) Effects of tyrosine and tryptophan ingestion on plasma catecholamine and 3, 4-dihydroxyphenylacetic acid concentrations. The journal of clinical endocrinology \& metabolism, 57, 760-763.

Ravi J, Devaraj K (1991) Quantitative essential amino acid requirements for growth of catla, Catla catla (Hamilton). Aquaculture, 96, 281-291. 
Reiter R, King T, Steinlechner S, Steger R, Richardson B (1990) Tryptophan administration inhibits nocturnal $\mathrm{N}$-acetyltransferase activity and melatonin content in the rat pineal gland. Neuroendocrinology, 52, 291-296.

Reyes-Gonzales M, Fuentes-Broto L, Martínez-Ballarín E, Miana-Mena F, Berzosa C, García-Gil F, Aranda M, García J (2009) Effects of tryptophan and 5hydroxytryptophan on the hepatic cell membrane rigidity due to oxidative stress. $J$. Membr. Biol., 231, 93-99.

Roméo M, Bennani N, Gnassia-Barelli M, Lafaurie M, Girard JP (2000) Cadmium and copper display different responses towards oxidative stress in the kidney of the sea bass Dicentrarchus labrax. Aquat. Toxicol., 48, 185-194.

Rubio V, Sánchez-Vázquez F, Madrid J (2006) Oral serotonin administration affects the quantity and the quality of macronutrients selection in European sea bass Dicentrarchus labrax L. Physiol. Behav., 87, 7-15.

Sadeghnia HR, Kamkar M, Assadpour E, Boroushaki MT, Ghorbani A (2013) Protective effect of safranal, a constituent of Crocus sativus, on quinolinic acid-induced oxidative damage in rat hippocampus. Iranian journal of basic medical sciences, 16, 73-82.

Saito S, Tachibana T, Choi Y-H, Denbow DM, Furuse M (2005) ICV melatonin reduces acute stress responses in neonatal chicks. Behav. Brain Res., 165, 197-203.

Sakkas P, Jones LA, Houdijk JG, Athanasiadou S, Knox DP, Kyriazakis I (2013) Leucine and methionine deficiency impairs immunity to gastrointestinal parasites during lactation. Br. J. Nutr., 109, 273-282.

Sanchez S, Sanchez CL, Paredes SD, Rodriguez AB, Barriga C (2008) The effect of tryptophan administration on the circadian rhythms of melatonin in plasma and the pineal gland of rats. Journal of applied biomedicine, 6, 177-186.

Sanchez W, Palluel O, Meunier L, Coquery M, Porcher J-M, Ait-Aissa S (2005) Copperinduced oxidative stress in three-spined stickleback: relationship with hepatic metal levels. Environ. Toxicol. Pharmacol., 19, 177-183.

Santamaría A, Galván-Arzate S, Lisý V, Ali SF, Duhart HM, Osorio-Rico L, Ríos C, Sut'astný F (2001) Quinolinic acid induces oxidative stress in rat brain synaptosomes. Neuroreport, 12, 871-874.

Santiago CB, Lovell RT (1988) Amino acid requirements for growth of Nile tilapia. The journal of nutrition, 118, 1540-1546.

Sarikaya S, Gulcin I (2013) Radical scavenging and antioxidant capacity of serotonin. Current bioactive compounds, 9, 143-152.

Serrano AE, Nagayama F (1992) Activity and partial purification of liver tryptophan pyrrolase in rainbow trout. Nippon suisan gakkaishi, 58, 2367-2371.

Shanks WE, Gahimer GD, Halver JE (1962) The indispensable amino acids for rainbow trout. The progressive fish-culturist, 24, 68-73.

Sharma MD, Baban B, Chandler P, Hou D-Y, Singh N, Yagita H, Azuma M, Blazar BR, Mellor AL, Munn DH (2007) Plasmacytoid dendritic cells from mouse tumordraining lymph nodes directly activate mature Tregs via indoleamine 2, 3dioxygenase. The journal of clinical investigation, 117, 2570-2582.

Stolte EH, Nabuurs SB, Bury NR, Sturm A, Flik G, Savelkoul HF, Verburg-van Kemenade BL (2008) Stress and innate immunity in carp: corticosteroid receptors and pro-inflammatory cytokines. Mol. Immunol., 46, 70-79. 
Suárez M, Martínez T, Abellán E, Arizcun M, Pérez-Jiménez A, Hidalgo M, Cardenete G (2009) The effects of the diet on flesh quality of farmed dentex (Dentex dentex). Aquaculture, 288, 106-113.

Tan D-X, Manchester LC, Esteban-Zubero E, Zhou Z, Reiter RJ (2015) Melatonin as a potent and inducible endogenous antioxidant: synthesis and metabolism. Molecules, 20, $18886-18906$.

Tang L, Feng L, Sun C-Y, Chen G-F, Jiang W-D, Hu K, Liu Y, Jiang J, Li S-H, Kuang S-Y (2013) Effect of tryptophan on growth, intestinal enzyme activities and TOR gene expression in juvenile Jian carp (Cyprinus carpio var. Jian): Studies in vivo and in vitro. Aquaculture, 412, 23-33.

Tejpal CS, Pal AK, Sahu NP, Ashish Kumar J, Muthappa NA, Vidya S, Rajan MG (2009) Dietary supplementation of 1-tryptophan mitigates crowding stress and augments the growth in Cirrhinus mrigala fingerlings. Aquaculture, 293, 272-277.

Torres-Farfan C, Richter HG, Rojas-García P, Vergara M, Forcelledo ML, Valladares LE, Torrealba F, Valenzuela GJ, Serón-Ferré M (2003) mt1 Melatonin receptor in the primate adrenal gland: inhibition of adrenocorticotropin-stimulated cortisol production by melatonin. The journal of clinical endocrinology \& metabolism, 88, 450-458.

Tsai C-L, Jang T-H, Wang L-H (1995) Effects of mercury on serotonin concentration in the brain of tilapia, Oreochromis mossambicus. Neurosci. Lett., 184, 208-211.

Velarde E, Delgado M, Alonso-Gómez A (2010) Serotonin-induced contraction in isolated intestine from a teleost fish (Carassius auratus): characterization and interactions with melatonin. Neurogastroenterol. Motil., 22, e364-e373.

Verburg-van Kemenade L, Ribeiro C, Chadzinska M (2011) Neuroendocrine-immune interaction in fish: Differential regulation of phagocyte activity by neuroendocrine factors. Gen. Comp. Endocrinol., 172, 31-38.

Verburg-Van Kemenade BL, Stolte EH, Metz JR, Chadzinska M (2009) Neuroendocrineimmune interactions in teleost fish. In: Fish physiology, pp. 313-364.

Vutukuru SS, Chintada S, Madhavi KR, Rao JV, Anjaneyulu Y (2006) Acute effects of copper on superoxide dismutase, catalase and lipid peroxidation in the freshwater teleost fish, Esomus danricus. Fish Physiol. Biochem., 32, 221-229.

Walton M, Coloso RM, Cowey C, Adron J, Knox D (1984) The effects of dietary tryptophan levels on growth and metabolism of rainbow trout (Salmo gairdneri). Br. J. Nutr., 51, 279-287.

Walton M, Cowey C, Coloso RM, Adron J (1986) Dietary requirements of rainbow trout for tryptophan, lysine and arginine determined by growth and biochemical measurements. Fish Physiol. Biochem., 2, 161-169.

Wei K, Yang J (2016) Copper-induced oxidative damage to the prophenoloxidaseactivating system in the freshwater crayfish Procambarus clarkii. Fish Shellfish Immunol., 52, 221-229.

Wen H, Feng L, Jiang W, Liu Y, Jiang J, Li S, Tang L, Zhang Y, Kuang S, Zhou X (2014) Dietary tryptophan modulates intestinal immune response, barrier function, antioxidant status and gene expression of TOR and Nrf2 in young grass carp (Ctenopharyngodon idella). Fish Shellfish Immunol., 40, 275-287.

Wilson R, Cowey C (1985) Amino acid composition of whole body tissue of rainbow trout and Atlantic salmon. Aquaculture, 48, 373-376. 
Wilson RP (2002) Amino acids and proteins. In: Fish nutrition (ed. by Halver J, Hardy RW). Academic Press, New York, USA, pp. 143-179.

Wilson RP, Allen Jr OW, Robinson EH, Poe WE (1978) Tryptophan and threonine requirements of fingerling channel catfish. The journal of nutrition, 108, 15951599.

Winberg S, Lepage O (1998) Elevation of brain 5-HT activity, POMC expression, and plasma cortisol in socially subordinate rainbow trout. American journal of physiology-regulatory, integrative and comparative physiology, 274, R645-R654.

Winberg S, Nilsson GE (1993) Time course of changes in brain serotonergic activity and brain tryptophan levels in dominant and subordinate juvenile Arctic charr. J. Exp. Biol., 179, 181-195.

Winberg S, Øverli Ø, Lepage O (2001) Suppression of aggression in rainbow trout (Oncorhynchus mykiss) by dietary L-tryptophan. J. Exp. Biol., 204, 3867-3876.

Winberg S, Winberg Y, Fernald RD (1997) Effect of social rank on brain monoaminergic activity in a cichlid fish. Brain. Behav. Evol., 49, 230-236.

Wolkers CPB, Serra M, Hoshiba MA, Urbinati EC (2012) Dietary L-tryptophan alters aggression in juvenile matrinxa Brycon amazonicus. Fish Physiol. Biochem., 38, 819-827.

Wright N, Preslock JP (1975) Melatonin Inhibition of Pineal Enzymes in Coturnix Quail. Neuroendocrinology, 19, 177-184.

Wu G (2009) Amino acids: metabolism, functions, and nutrition. Amino Acids, 37, 1-17.

Wu G (2013) Functional amino acids in nutrition and health. Amino Acids, 45, 407-411.

Wu H, Aoki A, Arimoto T, Nakano T, Ohnuki H, Murata M, Ren H, Endo H (2015) Fish stress become visible: A new attempt to use biosensor for real-time monitoring fish stress. Biosens. Bioelectron., 67, 503-510.

$\mathrm{Xu} \mathrm{F}$, Li J, Ma K, Wang M (1996) Effects of melatonin on hypothalamic $\gamma-$ Aminobutyric acid, aspartic acid, glutamic acid, $\beta$-Endorphin and serotonin levels in male mice. Neurosignals, 4, 225-231.

Yambe H, Kitamura S, Kamio M, Yamada M, Matsunaga S, Fusetani N, Yamazaki F (2006) L-Kynurenine, an amino acid identified as a sex pheromone in the urine of ovulated female masu salmon. In: Proceedings of the National Academy of Sciences, pp. 15370-15374.

Yanez J, Meissl H (1995) Secretion of Methoxyindoles from Trout Pineal Organs inVitro - Indication for a Paracrine Melatonin Feedback. Neurochem Int, 27, 195200.

Young M, Matthews J (1995) Serotonin regulation of T-cell subpopulations and of macrophage accessory function. Immunology, 84, 148.

Yuasa HJ, Mizuno K, Ball HJ (2015) Low efficiency IDO2 enzymes are conserved in lower vertebrates, whereas higher efficiency IDO1 enzymes are dispensable. FEBS journal, 282, 2735-2745.

Yuasa HJ, Takubo M, Takahashi A, Hasegawa T, Noma H, Suzuki T (2007) Evolution of vertebrate indoleamine 2,3-dioxygenases. J Mol Evol, 65, 705-714.

Yui R, Nagata Y, Fujita T (1988) Immunocytochemical Studies on the Islet and the Gut of the Arctic Lamprey, Lampetra-Japonica. Arch Histol Cytol, 51, 109-119. 
1466 Zaminhan M, Boscolo WR, Neu DH, Feiden A, Furuya VRB, MassamituFuruya W 1467 (2017) Dietary tryptophan requirements of juvenile Nile tilapia fed corn-soybean 1468 meal-based diets. Animal feed science and technology.

1469

1470 
1472 Table 1: Dietary tryptophan requirement (per cent of dietary protein level) in different 1473 teleosts

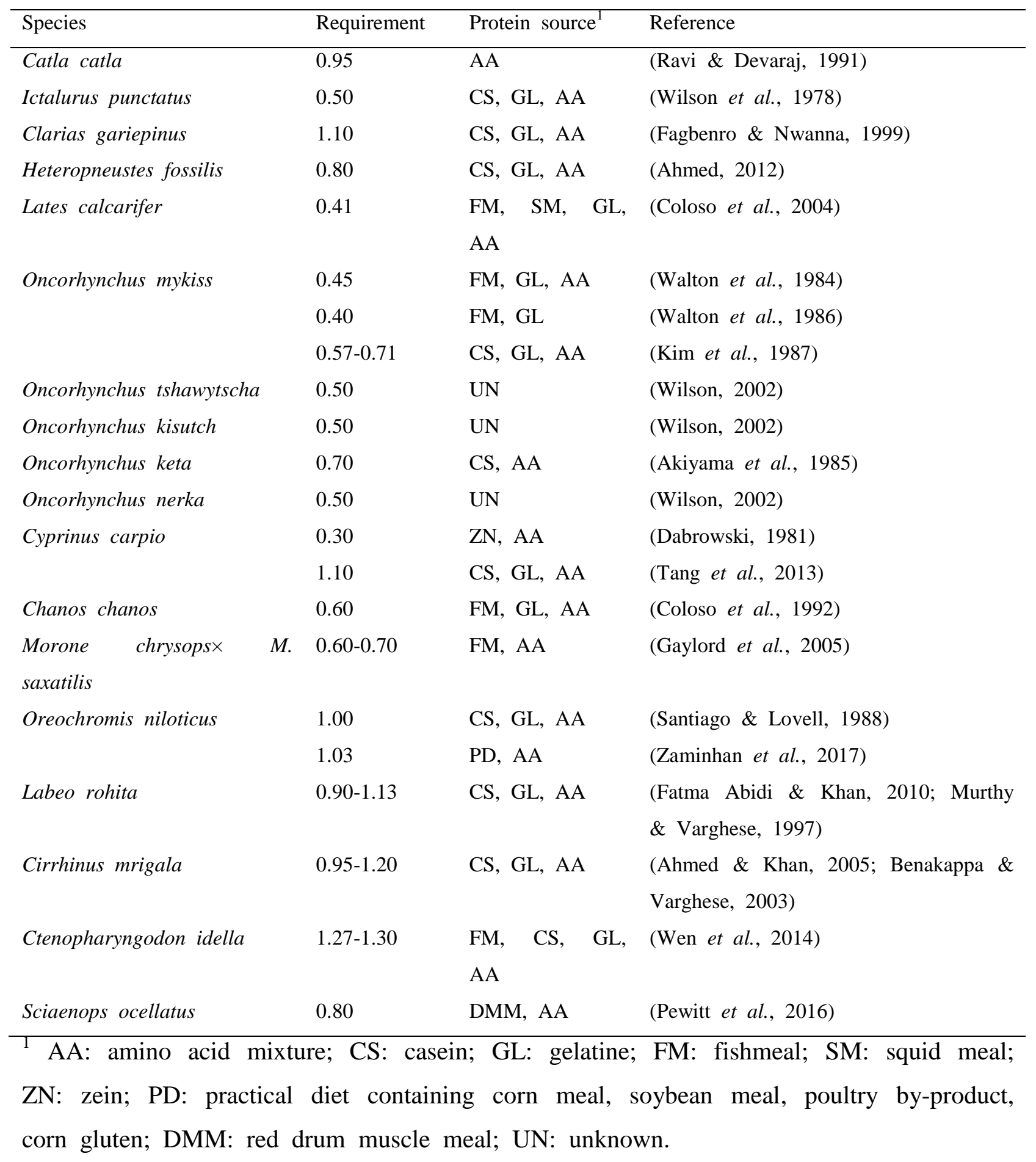


A

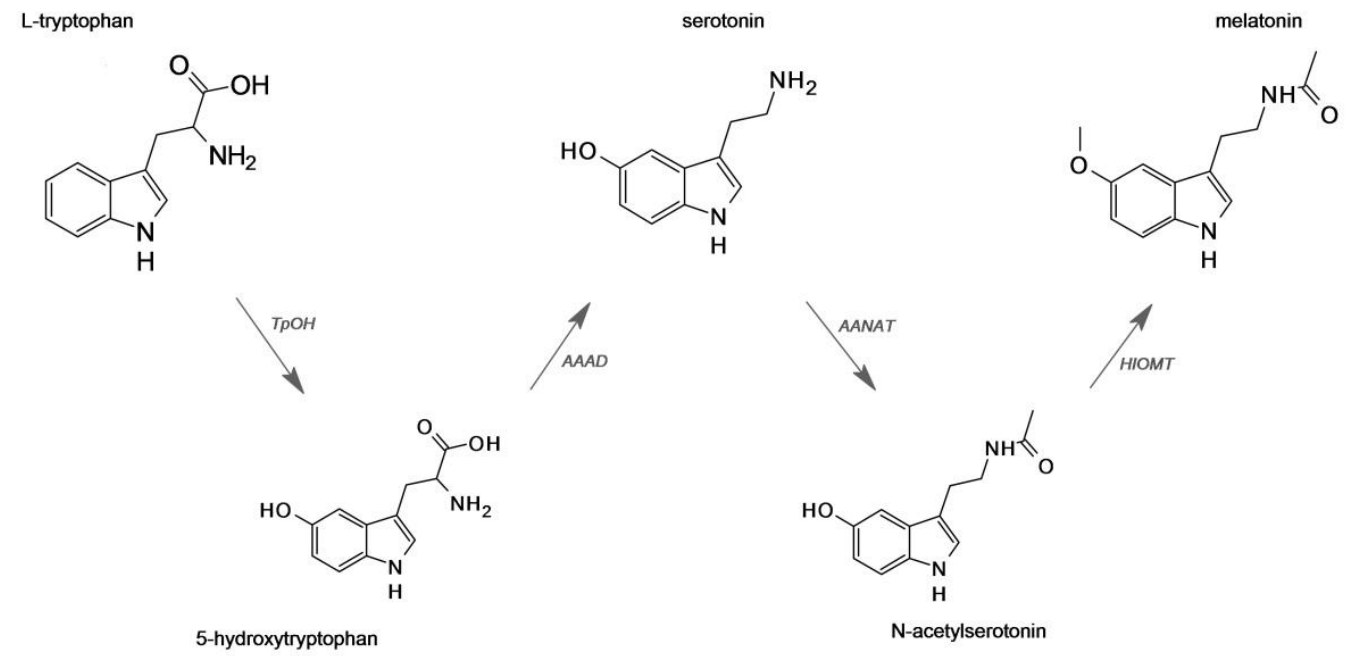

B

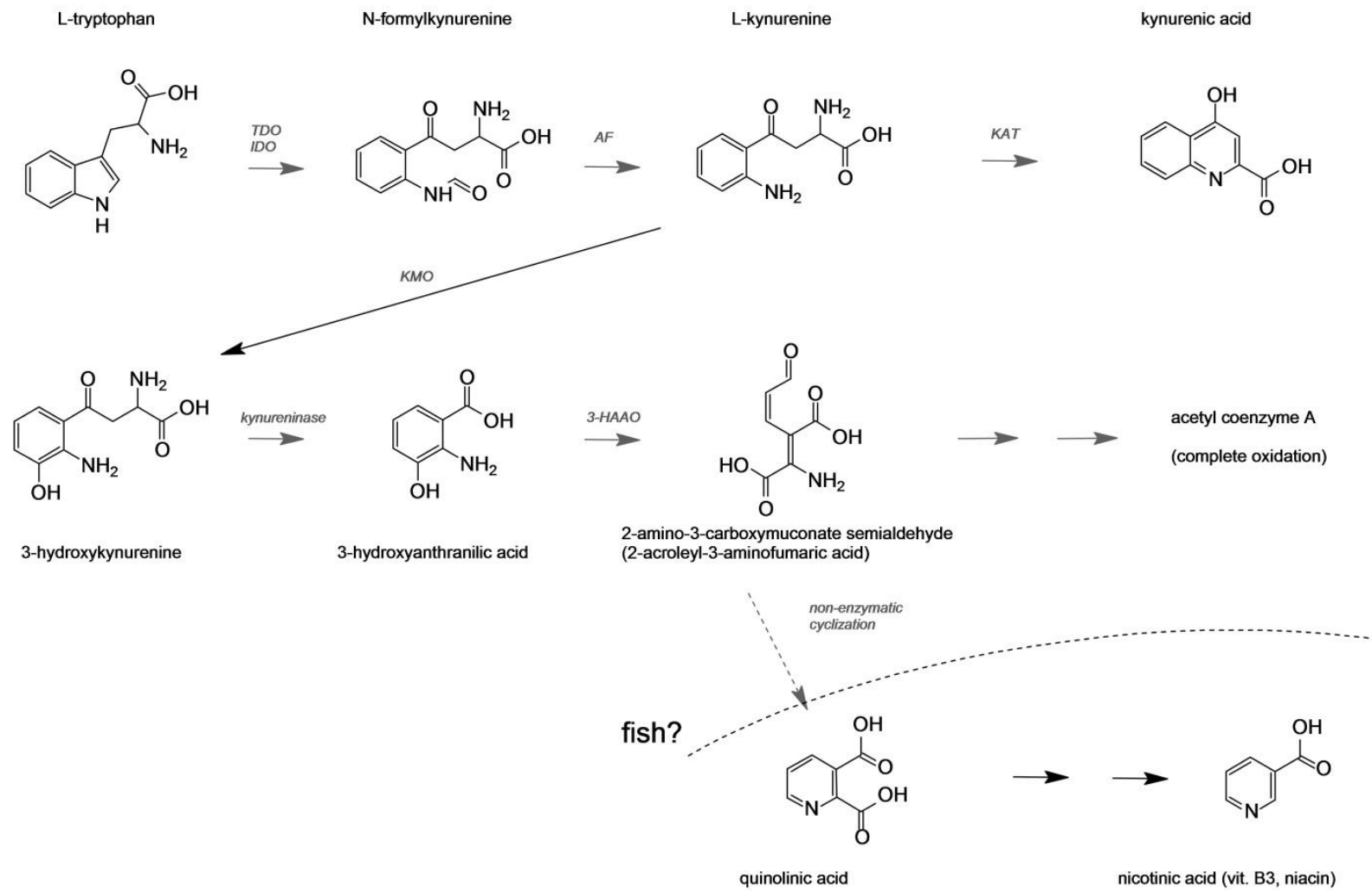

1479 Fig. 1. General L-tryptophan metabolic routes (besides its role as a component for 1480 protein synthesis) in vertebrates. A) Serotonin and melatonin biosynthetic pathways from 
1481 L-tryptophan and B) Main catabolic route for L-tryptophan (kynurenine pathway) 1482 (Badawy, 2017; Falcón et al., 2010; Fernstrom, 2016; Macchiarulo et al., 2009). In fish, 1483 the routes leading to the production of serotonin and melatonin are well established and 1484 known to be similar to those of other vertebrates. However, further research is still 1485 needed regarding the functionality of the kynurenin-niacin pathway, especially in what 1486 concerns the branch leading to the production of niacin (separated by a red line and 1487 arrow in the picture), which is well established in mammals but has not been confirmed 1488 in fish as yet (see the main text for further details). TpOH: tryptophan hydroxylase; $1489 A A A D$ : aromatic amino acid decarboxylase; AANAT: aryl-alkylamine-N-acetyltransferase; 1490 HIOMT: hydroxyindole- $O$-methyltransferase; TDO: tryptophan 2,3-dioxygenase; IDO: 1491 indoleamine 2,3-dioxygenase; $A F$ : arylformamidase; KAT: kynurenine aminotransferase; 1492 KMO: kynurenine 3-monooxygenase; 3-HAAO: 3-hydroxyanthranilic acid 3,4-dioxygenase. 


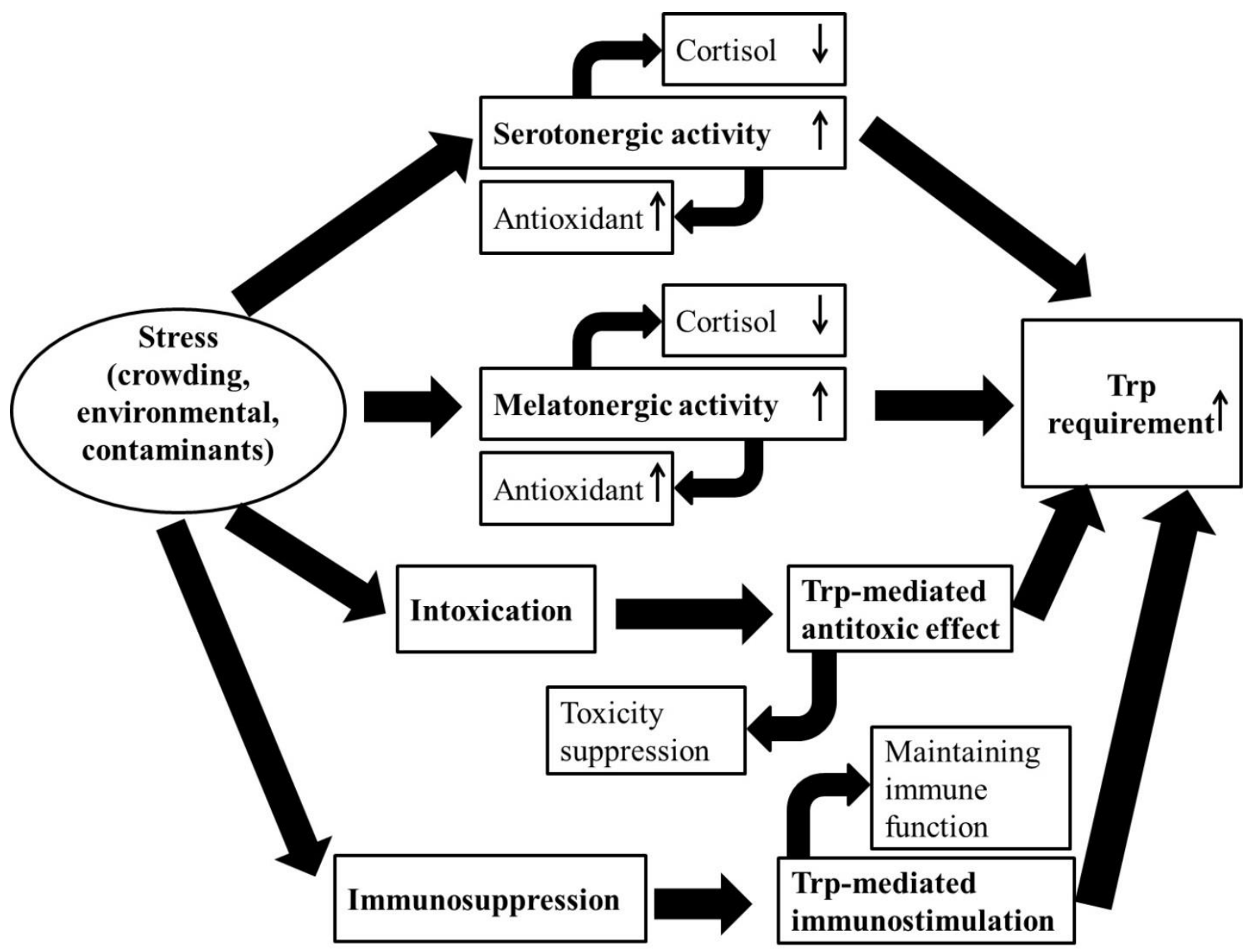

1495 Fig. 2: Factors affecting teleosts' dietary tryptophan requirement 